\title{
Comparison of Assessment of Citrus Canker Foliar Symptoms by Experienced and Inexperienced Raters
}

\author{
C. H. Bock, University of Florida/USDA, 2001 S. Rock Rd., Ft. Pierce, FL 34945; P. E. Parker and A. Z. Cook, \\ USDA-APHIS-PPQ, Moore Air Base, Edinburg, TX 78539; T. Riley, USDA-APHIS-PPQ, 800 Thorpe Road, Or- \\ lando, FL 32824; and T. R. Gottwald, USDA-ARS-USHRL, 2001 S. Rock Rd., Ft. Pierce, FL 34945
}

\begin{abstract}
Bock, C. H., Parker, P. E., Cook, A. Z., Riley, T., and Gottwald, T. R. 2009. Comparison of assessment of citrus canker foliar symptoms by experienced and inexperienced raters. Plant Dis. 93:412-424

Citrus canker (Xanthomonas citri subsp. citri) is destructive in many citrus production regions in tropical and subtropical parts of the world. Assessment of canker symptoms is required for diverse reasons, including monitoring epidemics, evaluating the efficacy of control strategies, and disease response in breeding material. The objectives were to compare the ability of experienced and inexperienced raters at assessing citrus canker, to identify factors that affect the quality of the assessment, to determine common sources of error, and to discern how error is related to actual disease magnitude. Two-hundred digital leaf images (0 to $37 \%$ area infected) were assessed once by 28 raters, five of whom were experienced plant pathologists (PPs), and 23 who had no experience in disease severity assessment (NPPs). True disease (lesion number [LN], \% necrotic area $[\% \mathrm{~N}]$, and $\%$ chlorotic+necrotic area $[\% \mathrm{CN}])$ was measured using image analysis on a leaf-by-leaf basis, and each parameter was estimated by the 28 raters. LN was neither severely over- nor underestimated, while $\% \mathrm{~N}$ was greatly overestimated, with a lesser tendency to overestimate $\% \mathrm{CN}$ over the true severity range of these two symptom types. A linear relationship existed between estimate of the disease and true disease for all measures of severity. Data were heteroscedastic and error was not constant with increasing true disease. Agreement between rater estimates and true disease was measured with Lin's concordance correlation coefficient $\left(\rho_{c}\right)$. LN showed greatest agreement ( $\rho_{c}=0.88$ to 0.99$)$, followed by $\% \mathrm{CN}\left(\rho_{c}=0.80\right.$ to 0.95$)$ and $\% \mathrm{~N}\left(\rho_{c}\right.$ $=0.19$ to 0.84 ). Greater lesion number resulted in overestimation of area infected for both $\% \mathrm{~N}$ and $\% \mathrm{CN}$. Overestimation was particularly noticeable at low disease severities. There was a linear relationship between log variance and $\log$ true disease for $\mathrm{LN}\left(r^{2}=0.71\right), \% \mathrm{~N}\left(r^{2}=0.85\right)$, and $\% \mathrm{CN}\left(r^{2}=0.88\right)$, and raters tended to estimate disease above $10 \%$ to the nearest 5 or $10 \%$. GLM analysis showed differences between PP and NPP groups in assessing disease. For LN, precision of assessment for both groups was similar $\left(r^{2}>0.92\right.$ and 0.94 , respectively), but for estimates of $\% \mathrm{~N}$ and $\% \mathrm{CN}$, the PPs were more precise $\left(\% \mathrm{~N}\right.$ and $\% \mathrm{CN}, r^{2}=0.61$ and 0.73 , respectively) compared to NPPs ( $\% \mathrm{~N}$ and $\% \mathrm{CN}, r^{2}=0.45$ and 0.58 , respectively). Absolute error for mean $\mathrm{LN}$ was low. The absolute error of $\% \mathrm{~N}$ and $\% \mathrm{CN}$ showed overestimation to approximately $8 \%$ area infected. Above $8 \%$, absolute error increased, but comprised both over- and underestimation. For $\% \mathrm{~N}$ and $\% \mathrm{CN}$, relative error was almost exclusively positive and dramatic at severity $<8 \%$ (up to approximately $600 \%$ ), but at severity $>10 \%$ it was relatively small. Error in rater estimates of canker severity is ubiquitous. Understanding these sources of error will aid in the development of both appropriate training and relevant rating aids.
\end{abstract}

Citrus canker (Xanthomonas citri subsp. citri) can cause severe infection of commercial citrus. It is particularly problematic in wetter tropical and subtropical citrus producing areas (36). Infection results in direct yield loss, fruit drop, and severely blemished fruit (36). In Florida, citrus canker was under eradication until early in 2006, when the Citrus Canker Eradication Program (CCEP) was terminated $(12,21)$. Other approaches to manage, reduce, and contain the disease remain viable, and

Corresponding author: Clive Bock

E-mail: clive.bock@ars.usda.gov

Accepted for publication 7 December 2008.

doi:10.1094/PDIS-93-4-0412

(C) 2009 The American Phytopathological Society tion, which expands in size ( 3 to $5 \mathrm{~mm}$ ), developing a chlorotic halo and eventually a raised, necrotic center, which senesces, resulting in a patch of dead tissue on the leaf surface. There are various measures for assessing how severe these symptoms are, which include counting the number of lesions per unit or estimating the area infected, both of which can be useful measures in studying aspects of the disease. Some studies of plant disease symptoms have considered the relationship between lesion number and lesion area $(6,7,29,38)$. How the different components of citrus canker symptom types relate to each other, and how they might influence estimation of area, including aspects that change during symptom development, are only partially understood $(5,6)$.

Rater ability has been established as error-prone in many pathosystems $(1,15,29$, $34,35,38)$, including citrus canker assessment $(3,5,6)$. Disease assessments may be made directly and unaided, or with the aid of standard area diagrams or different kinds of training prior to assessment (3). Training and the use of assessment aids were shown to reduce error in most cases $(28,31,35)$. However, knowledge of the ability to assess disease directly (without the aid of standard area diagrams or training) is of value, as this baseline information on rater ability is a measure of the magnitude and location or cause of the error, thus providing a benchmark for gauging the value of training or the use of standard area diagrams for assessment $(3,28,29,31,35)$. It also provides a basis for comparing automated systems such as image analysis or reflectance radiometry in relation to the spectrum of ability of raters $(5,34)$.

Various definitions and concepts are used to discern the quality of estimates in measurement science and plant pathology $(26,32)$. We use terms and concepts sensu Madden et al. (26). Among raters, the inter- and intrarater reliability (ability of raters to achieve the same result) describes variability associated with the estimates, while the agreement (or accuracy) of the estimates describes how close they are to a known true, actual, or "golden standard" value. The range of ability among individuals in assessing disease is reflected in the reliability of the estimates. The characteristics of agreement of an estimate with the true value involve elements of preci- 
sion and accuracy. Agreement is known to depend not only on individual ability, assessment aids, or training $(28,31,35)$, but also on facets of the disease symptoms themselves, such as lesion number and size relative to area infected $(6,29,38)$. If sources of error were ubiquitous or constant among raters, then it would be possible to apply a calibration procedure to account for the error. Unfortunately, this is not the case, and although calibration of error may sometimes be possible at individual levels (37), it is probably impractical for many cases. Other more global cures for rater error have been attempted. The Horsfall-Barratt scale (18-20) was developed to account for a perceived (but not empirically demonstrated) source of error in disease estimation, claiming that ability to estimate disease was logarithmically related to true disease. The assumption that the estimate is related to the logarithm of the true disease has been questioned $(17,29-31)$, and most studies now demonstrate that a direct linear relationship exists between true and estimated disease $(5,6,29-31)$.

However, the ability to directly estimate disease might have a nonconstant relationship as true disease severity increasesthat is to say the variance, or error of estimation, might be greater at certain severities than at others $(6,10,11,15)$. However, at least one study has found that magnitude of true disease per se did not influence the error of the estimate (29). Nonconstancy of error that appears to accompany true disease remains poorly characterized in disease assessment studies, and if these data are sometimes heteroscedastic, the reasons should be understood to facilitate improvement of disease assessment. In addition, nonconstancy of error may make certain assumptions and analyses inappropriate. Some raters have a tendency to estimate disease severity in "knots"-a preference for certain numbers $(5,15$, $22,35)$. If this is the case, then it suggests the percent scale is not applied as a truly continuous scale during direct estimation (it starts to take on characteristics of a categorical scale). Disease rating on a continuous scale should not be characterized by preferred values if estimates are to be in agreement with true values.

Although variance of the estimate (and therefore the standard deviation and error) might increase with magnitude of true disease, the ability to estimate disease at low levels of severity is also flawed $(4,7)$. The absolute and relative errors can be useful in providing insight into the magnitude of error at different true disease severities, and how this influences the accuracy at particular true severities. An absolute error of $2 \%$ is different at $35 \%$ compared to $3 \%$ true disease; while the former is a relative error of $5.7 \%$, the latter is a relative error of $66.7 \%$, resulting in a relatively less accurate estimate of the true disease. Apart from gaining insight into the error that exists in disease assessment, it also provides information that can be used to improve assessment over the spectrum of disease severity.

There is little data available from the science of psychophysics for us to extrapolate to disease assessment, and most studies in psychophysics have dealt with perception of stimuli other than the percent area, including brightness, weight, etc.; and although some of these are quite well characterized $(2,9,39,40)$, area estimation is not $(2,16,30)$. However, various factors have been demonstrated to influence the estimate, including lesion number. With leaf spotting diseases, there is a tendency to overestimate area at high lesion counts, and disease overestimation is particularly apparent at low disease severity $(1,6$, 29,38).

Only a few studies in a handful of pathosystems have assessed characteristics of disease assessment by large, diverse groups of raters and the characteristics of the errors identified and described. Ability of assessors is variable and may change from one assessment to the next $(5,28,29,31,34,35)$. Some factors, such as

Table 1. The mean, range, and standard deviation ${ }^{\mathrm{a}}$ of estimates of number of lesions of citrus canker, $\%$ leaf area necrotic and $\%$ leaf area chlorotic+necrotic infected with citrus canker for 200 grapefruit leaves assessed by image analysis and 28 raters ${ }^{\mathrm{b}}$

\begin{tabular}{|c|c|c|c|c|c|c|c|c|c|}
\hline \multirow[b]{2}{*}{ Rater $^{c}$} & \multicolumn{3}{|c|}{ Lesion count ( $\mathbf{L N})$} & \multicolumn{3}{|c|}{$\%$ area necrotic $(\% \mathbf{N})$} & \multicolumn{3}{|c|}{$\%$ area chlorotic+necrotic $(\% \mathrm{CN})$} \\
\hline & Mean & Range (max) & St dev & Mean & Range (max) & St dev & Mean & Range (max) & St dev \\
\hline IA & 12.3 & 102 & 16.3 & 1.6 & 8.6 & 2.0 & 6.6 & 36.7 & 8.0 \\
\hline Rater $1 \mathrm{pp}$ & 11.9 & 108 & 16.9 & 2.3 & 10.0 & 1.7 & 4.9 & 27.0 & 4.7 \\
\hline Rater 2 pp & 10.7 & 84 & 15.4 & 3.4 & 18.0 & 3.5 & 5.8 & 27.0 & 5.4 \\
\hline Rater $3 \mathrm{pp}$ & 13.5 & 116 & 19.5 & 2.4 & 10.0 & 2.3 & 6.3 & 40.0 & 6.5 \\
\hline Rater 4 pp & 10.4 & 87 & 14.2 & 2.3 & 40.0 & 3.8 & 7.7 & 50.0 & 9.7 \\
\hline Rater 5 & 12.6 & 91 & 16.9 & 8.7 & 50.0 & 10.2 & 15.6 & 70.0 & 14.9 \\
\hline Rater 6 & 10.0 & 70 & 13.1 & 3.6 & 30.0 & 5.7 & 8.3 & 50.0 & 12.0 \\
\hline Rater 7 & 9.0 & 70 & 11.7 & 3.2 & 20.0 & 3.4 & 4.4 & 26.0 & 4.5 \\
\hline Rater 8 & 13.6 & 115 & 19.4 & 4.5 & 50.0 & 6.5 & 7.3 & 75.0 & 10.2 \\
\hline Rater 9 & 10.7 & 60 & 13.4 & 4.1 & 25.0 & 4.7 & 6.0 & 35.0 & 6.6 \\
\hline Rater 10 & 10.9 & 91 & 15.4 & 5.3 & 50.0 & 8.1 & 7.2 & 90.0 & 10.6 \\
\hline Rater 11 & 12.8 & 112 & 18.3 & 2.5 & 13.0 & 2.7 & 5.2 & 24.0 & 5.6 \\
\hline Rater 12 & 12.0 & 101 & 17.2 & 7.2 & 50.0 & 7.8 & 10.4 & 60.0 & 10.2 \\
\hline Rater 13 & 12.8 & 117 & 18.3 & 1.4 & 8.0 & 1.3 & 2.0 & 10.0 & 2.1 \\
\hline Rater 14 & 11.8 & 80 & 16.0 & 2.5 & 18.0 & 3.4 & 5.9 & 35.0 & 6.2 \\
\hline Rater 15 & 12.8 & 106 & 17.7 & 2.3 & 12.0 & 1.9 & 7.5 & 50.0 & 9.2 \\
\hline Rater 16 & 12.6 & 115 & 18.5 & 3.6 & 20.0 & 4.3 & 7.0 & 40.0 & 8.3 \\
\hline Rater 17 & 11.7 & 80 & 15.5 & 9.7 & 70.0 & 12.6 & 13.1 & 80.0 & 15.3 \\
\hline Rater 18 & 11.8 & 95 & 16.7 & 3.7 & 20.0 & 2.8 & 7.5 & 26.0 & 5.0 \\
\hline Rater 19 & 12.5 & 100 & 17.0 & 6.4 & 35.0 & 7.2 & 13.3 & 68.0 & 14.4 \\
\hline Rater 20 & 11.6 & 90 & 16.0 & 4.4 & 20.0 & 4.2 & 10.2 & 45.0 & 9.2 \\
\hline Rater 21 & 11.1 & 80 & 15.4 & 6.1 & 35.0 & 7.5 & 9.5 & 45.0 & 10.9 \\
\hline Rater 22 & 11.3 & 95 & 15.8 & 1.8 & 21.0 & 3.2 & 3.7 & 41.0 & 6.3 \\
\hline Rater 23 & 12.5 & 96 & 17.2 & 3.7 & 25.0 & 3.2 & 7.5 & 33.0 & 5.4 \\
\hline Rater 24 pp & 10.1 & 100 & 13.9 & 2.8 & 15.0 & 3.2 & 6.5 & 30.0 & 6.8 \\
\hline Rater 25 & 10.9 & 98 & 15.6 & 9.8 & 60.0 & 13.3 & 15.7 & 80.0 & 19.5 \\
\hline Rater 26 & 12.0 & 108 & 17.5 & 3.0 & 20.0 & 3.2 & 6.7 & 35.0 & 6.8 \\
\hline Rater 27 & 12.5 & 108 & 17.9 & 2.0 & 15.0 & 2.2 & 4.1 & 30.0 & 4.6 \\
\hline Rater 28 & 13.0 & 105 & 18.3 & 3.0 & 40.0 & 3.5 & 8.2 & 35.0 & 6.8 \\
\hline Mean & 11.9 & 93.8 & 16.3 & 4.2 & 22.6 & 4.4 & 7.8 & 38.4 & 7.9 \\
\hline
\end{tabular}

${ }^{\text {a }}$ Mean and standard deviation (st dev) are based on the mean of all 200 estimates per rater.

b All assessors recorded some leaves with 0 disease.

c pp indicates trained plant pathologists. 
training, do improve rater ability $(31,35)$ or the amount of time taken to perform the assessment (35).

To address some of these issues in the assessment of citrus canker, both experi- enced and inexperienced raters (career plant pathologists and surveyors from the CCEP) were asked to rate the severity of familiar symptoms of citrus canker. The objectives of the study were (i) to gauge how well experienced and inexperienced raters assessed different symptoms of citrus canker, (ii) to test whether this ability among raters related to various other factors including CCEP canker identification
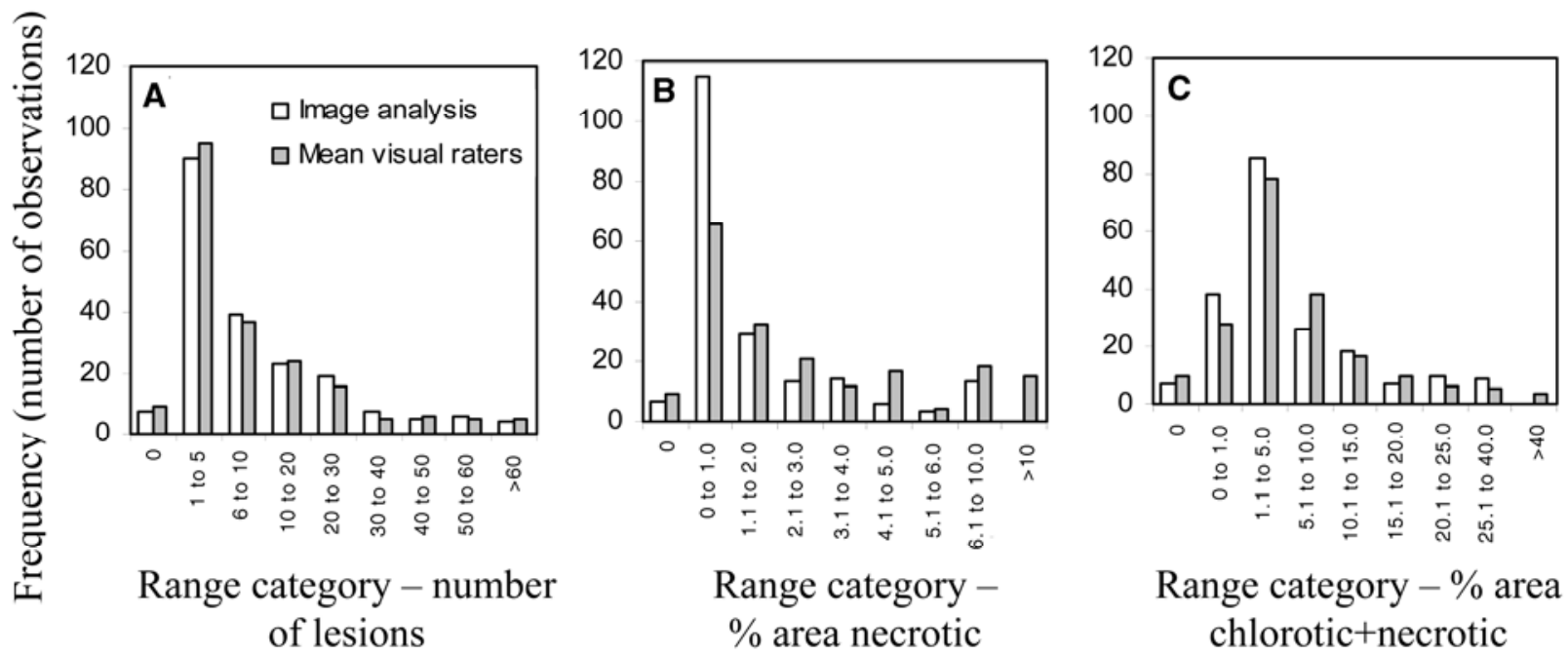

Fig. 1. Frequency of estimates of A, lesion numbers, B, \% leaf area necrotic, and $\mathbf{C}, \%$ leaf area chlorotic+necrotic for citrus canker symptoms on 200 grapefruit leaves assessed by image analysis and by 28 raters.

A
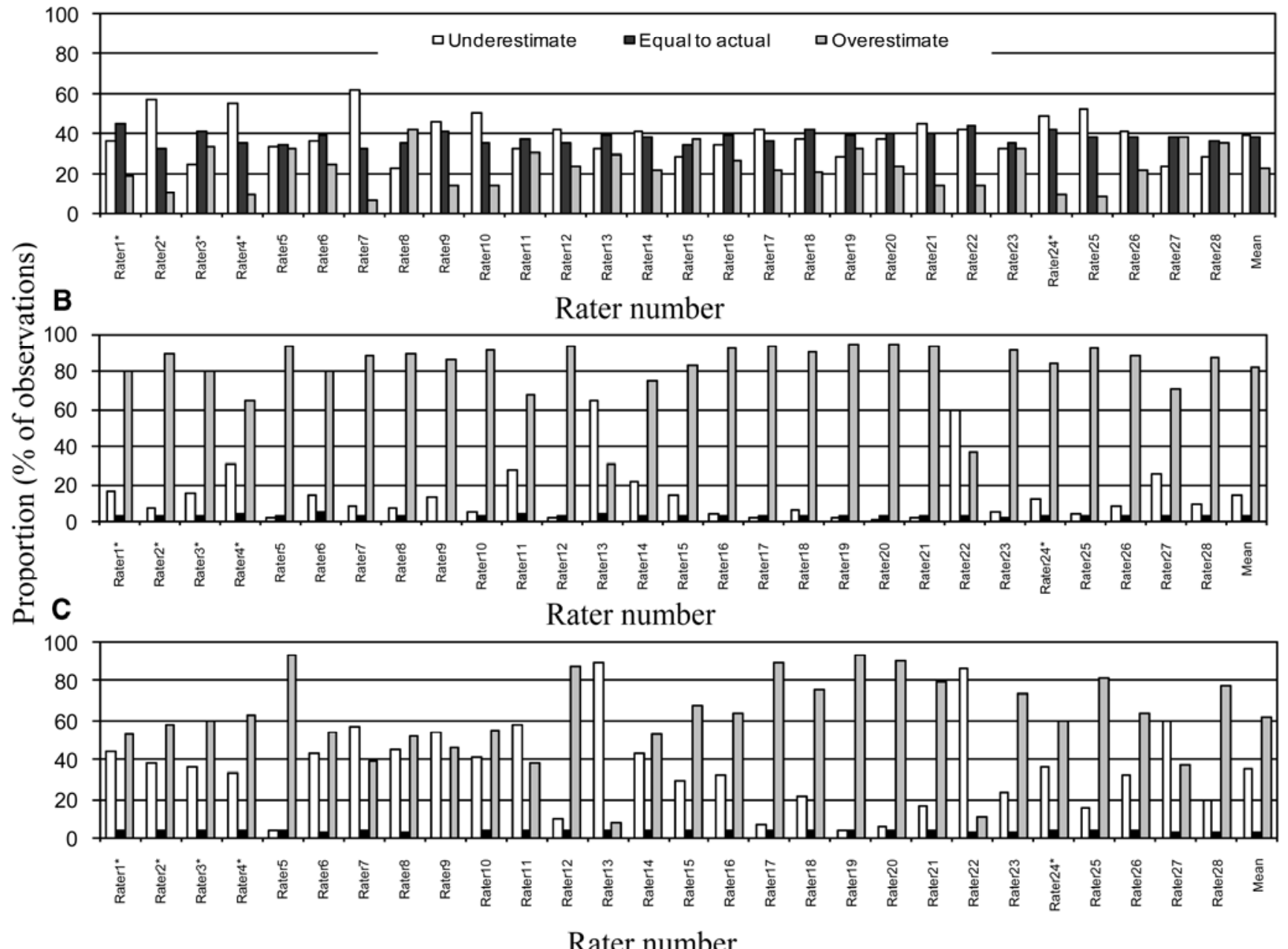

Rater number

Fig. 2. Frequency of correct values, over- and underestimates of A, lesion numbers, B, \% leaf area necrotic, and $\mathbf{C}$, \% leaf area chlorotic+necrotic for citrus canker symptoms on 200 grapefruit leaves assessed by 28 raters. * indicates trained plant pathologists. 
test score ratings, time taken to perform assessments, etc., (iii) to determine whether symptom type influenced quality of assessments among raters or rater groups, (iv) to identify common tendencies causing error among raters of citrus canker, (v) to assess how variance of the estimates changes with true disease severity for various symptoms and how well mean values reflect true disease, and (vi) to describe how absolute error and relative error change with true disease as severity of citrus canker increases.

\section{MATERIALS AND METHODS}

Leaves and leaf images. The leaves were collected from infected grapefruit trees in south Florida. All leaves were from plants collected by survey crews of the CCEP in 2005. Leaves were diseased at naturally occurring severity. The leaves were sampled arbitrarily from the bags of samples collected by the CCEP, including a few disease-free leaves. Leaves that had leaf miner damage or were incomplete, or leaves that were affected by symptoms of other diseases, were not used. A total of 200 were photographed using a 6.5 megapixel Canon EOS 10D digital camera (24-85 mm AF lens). The image analysis software Assess (American Phytopathological Society, St. Paul, MN) was used to count lesion number ( $\mathrm{LN})$ and measure area displaying necrosis $(\% \mathrm{~N})$ and chlorosis+necrosis $(\% \mathrm{CN})$ on a leaf-by-leaf basis. Details of the process of image analysis of canker specimens have been described previously $(5,6)$. Image size was standardized and printed $(8.25 \times 5.70 \mathrm{~cm})$ and approximately reflected the size of the leaf, with six images per page. Each of the images was assessed once visually by each of 28 raters and individually using image analysis for $\mathrm{LN}, \% \mathrm{~N}$, and $\% \mathrm{CN}$. The data from the image analysis assessments were assumed to be the true values, against which all rater results were compared for agreement (424).

Five of the raters were plant pathologists (PPs), experienced in the identification and assessment of severity of citrus canker. The remaining 23 raters were surveyors of the CCEP and not plant pathologists (NPPs), trained in the identification of citrus canker but with no formal training in disease severity assessment. Assessments were made individually, with no formal resting period, although brief breaks of a few minutes could be taken. In addition to rating disease, each individual provided additional data including age, gender, years of college, years as a graduate student, time spent as canker surveyor/plant pathologist, days of training on canker, whether canker had been seen in the field and when it was last seen (days), the number of days training in other pest and disease identification and assessment, test score ratings from the CCEP internal tests on canker identification, and duration of the assessment period. None of the plant pathologists involved had taken the CCEP internal tests and were thus omitted from that part of the analysis.

Data analysis. Data were analyzed using SAS (SAS Systems, Cary, NC). Regression analysis (PROC REG) was used to estimate the relationship of the different raters to the true disease $(5,6)$. A number of single- $(y=a+b x)$ and two-factor $(y=a+$ $b x+c x)$ models were tested to investigate whether area and/or lesion count influenced the relationship by incorporating different combinations of the independent variables lesion count $(L), \log _{e} L, \sqrt{ } L, \%$ area necrotic $(\% \mathrm{Nec}), \log _{e} \% \mathrm{Nec}, \sqrt{ } \% \mathrm{Nec}$, $\%$ area necrotic+chlorotic $(\% \mathrm{Nec}+\mathrm{Chl})$, $\log _{e} \% \mathrm{Nec}+\mathrm{Chl}$, $\sqrt{ } \% \mathrm{Nec}+\mathrm{Chl}$ (38). Heteroscedasticity of the data was tested using the Breusch-Pagan test, which is an analysis of the residuals of the fitted regression model. In addition, the slope, intercept coefficient of variation, and coefficient of determination were calculated, and residual plots were graphed to assess the fit of the regression solutions $(31,35)$. Furthermore, to test for effects of lesion number and area on any tendency to over- or underestimate disease, various two- and three-factor models were tested as described above to investigate the relationship between the ratio of rater estimate:true disease and true disease (38).
Characteristics of agreement (precision and accuracy, 26) of the disease assessments to true values were investigated for individual raters and mean assessment data (for $\mathrm{LN}, \% \mathrm{~N}$, and $\% \mathrm{CN}$ ) and rater groups (PPs and NPPs). Correlation analysis (PROC CORR) was used to assess precision of raters in relation to the true disease measured using image analysis, and indicates variability associated with the estimates. Lin's concordance correlation coefficient $(5,25,26,29)$ provides a quantifiable method to test agreement with a known true value (in this case that measured using image analysis). The coefficient $\left(\rho_{c}\right)$ is the product of elements of precision (correlation coefficient, $r)$ and accuracy $\left(C_{b}\right) . C_{b}$ is a generalized bias correction factor that measures accuracy and comprises two measures that account for scale or slope shifts (coefficient $v$, with a perfect relation of 1 between $X$ and $Y$ ) and a location or elevation shift (coefficient $\mu$, where 0 is a perfect relation between $X$ and $Y$ ).

Correlation analysis was used to determine association between rater ability to estimate disease and various rater characteristics (rater age [years], years of education, time worked as a surveyor [days], time trained in canker identification [days], recency of past canker finds in the field [days], days of other plant pest and disease identification and assessment training,

Table 2. Linear regression of true counts of lesion number vs. counts by 28 raters estimates on 200 grapefruit leaves infected with citrus canker ${ }^{\mathrm{a}}$

\begin{tabular}{|c|c|c|c|c|c|}
\hline Rater & $a$ & $b$ & $r^{2}$ & $C V$ & $\begin{array}{c}\text { B-P test } \\
(P>C \text { Chisq })\end{array}$ \\
\hline Rater 1 pp & $-0.75 * * *$ & $1.02 * * *$ & 0.98 & 21.4 & $39.6,<0.0001$ \\
\hline Rater 2 pp & -0.57 & $0.92 * * *$ & 0.94 & 34.3 & $45.2,<0.0001$ \\
\hline Rater 3 pp & $-1.03 * * *$ & $1.17 * * *$ & 0.97 & 24.6 & $51.4,<0.0001$ \\
\hline Rater 4 pp & 0.07 & $0.84 * * *$ & 0.93 & 36.6 & $30.3,<0.0001$ \\
\hline Rater 5 & 0.16 & $1.01 * * *$ & 0.96 & 26.1 & $64.3,<0.0001$ \\
\hline Rater 6 & -0.45 & $1.02 * * *$ & 0.96 & 25.2 & $42.4,<0.0001$ \\
\hline Rater 7 & 0.57 & $0.68 * * *$ & 0.91 & 39.8 & $62.3,<0.0001$ \\
\hline Rater 8 & $-0.75 * *$ & $1.17 * * *$ & 0.97 & 23.7 & $47.6,<0.0001$ \\
\hline Rater 9 & $0.93 * *$ & $0.79 * * *$ & 0.93 & 34.3 & $83.7,<0.0001$ \\
\hline Rater 10 & -0.39 & $0.91 * * *$ & 0.96 & 29.4 & $24.1,<0.0001$ \\
\hline Rater 11 & $-0.75^{* *}$ & $1.10 * * *$ & 0.97 & 25.0 & $36.4,<0.0001$ \\
\hline Rater 12 & $-0.77 * *$ & $1.04 * * *$ & 0.97 & 25.1 & $38.5,<0.0001$ \\
\hline Rater 13 & $-0.88 * *$ & $1.10 * * *$ & 0.97 & 25.7 & $34.4,<0.0001$ \\
\hline Rater 14 & 0.32 & $0.93 * * *$ & 0.91 & 40.5 & $51.6,<0.0001$ \\
\hline Rater 15 & -0.35 & $1.06 * * *$ & 0.97 & 26.0 & $38.3,<0.0001$ \\
\hline Rater 16 & $-1.03 * * *$ & $1.11 * * *$ & 0.97 & 23.4 & $36.0,<0.0001$ \\
\hline Rater 17 & 0.40 & $0.92 * * *$ & 0.93 & 35.1 & $25.5,<0.0001$ \\
\hline Rater 18 & -0.51 & $1.00 * * *$ & 0.96 & 27.1 & $51.2,<0.0001$ \\
\hline Rater 19 & -0.16 & $1.03 *$ & 0.97 & 20.1 & $53.7,<0.0001$ \\
\hline Rater 20 & 0.19 & $0.93 * * *$ & 0.91 & 42.5 & $14.6,<0.0001$ \\
\hline Rater 21 & $-0.14 * *$ & $0.92 * * *$ & 0.94 & 33.7 & $13.8,<0.0001$ \\
\hline Rater 22 & -0.41 & $0.95 * * *$ & 0.97 & 24.9 & $26.1,<0.0001$ \\
\hline Rater 23 & -0.20 & $1.03 * * *$ & 0.95 & 32.2 & $69.9,<0.0001$ \\
\hline Rater 24 pp & 0.47 & $0.78 * * *$ & 0.85 & 54.3 & $32.4,<0.0001$ \\
\hline Rater 25 & $-0.64^{*}$ & $0.93 * * *$ & 0.96 & 28.8 & $25.8,<0.0001$ \\
\hline Rater 26 & $-1.02 * * *$ & $1.06 * * *$ & 0.97 & 25.1 & $45.0,<0.0001$ \\
\hline Rater 27 & -0.25 & $1.03 * * *$ & 0.90 & 46.2 & $14.7,<0.0001$ \\
\hline Rater 28 & -0.56 & $1.10 * * *$ & 0.96 & 27.2 & $43.6,<0.0001$ \\
\hline Mean & -0.30 & $0.98 * * *$ & 0.98 & 21.0 & $33.0,<0.0001$ \\
\hline
\end{tabular}

a Linear regression where the model $y=a+b x$ represents estimated number of lesions, where $x$ is the true number of lesions, $a$ is the intercept, and $b$ the slope parameter. Actual lesion number measured with image analysis, mean $=$ average of all 28 raters. $r^{2}=$ coefficient of determination, $C V=$ coefficient of variation of the regression. $* * *, P<0.001 ; * *, P<0.01 ; *, P<0.05$. Breusch-Pagan (B-P) test checks for heteroscedasticity. ${ }^{\mathrm{pp}}$ indicates trained plant pathologists. 
CCEP test scores [TS, for 2002, 2003, 2004, 2005, 2006, 2007, and average score], and the time [hours] taken to assess all 200 images). Statistics that indicated the quality of the assessment of $\mathrm{LN}, \% \mathrm{~N}$, and $\% \mathrm{CN}$ by each individual included mean disease severity, variance, standard deviation, scale $(v)$ or locational $(\mu)$ shifts, $C_{b}, \rho_{c}$, or $r$ (true versus estimated severity). A $t$ test was performed to test whether there was any effect of gender on estimation of disease. The assessments by the two groups, PPs and NPPs, were directly compared using general linear modeling (PROC GLM) for both individual data and the means of the groups. In this analysis, the regression slopes are tested to see if there are differences in the dependent variable ( $d v$, disease severity) due to the independent variable of class ( $g$, group) when compared to the continuous independent variable, the regressor $(r$, true disease severity). A test for interaction between regressor and group $\left(d v=r, g, r^{*} g\right)$ gauges whether there are class differences which are reflected in slope for the two groups. If the interaction term is significant, then the groups are different. If the interaction is not different, a further test for differences in the elevation of the regression lines (a test of parallelism) is required, which is achieved by running GLM on the reduced model (no interaction term, $d v=r, g$ ). If there is a significant class $(g)$ effect, the two groups have different elevations but the same slope. All individual data from each group were compared. The precision of the estimates was also compared using the coefficient of determination $\left(r^{2}\right)$ of the regression.
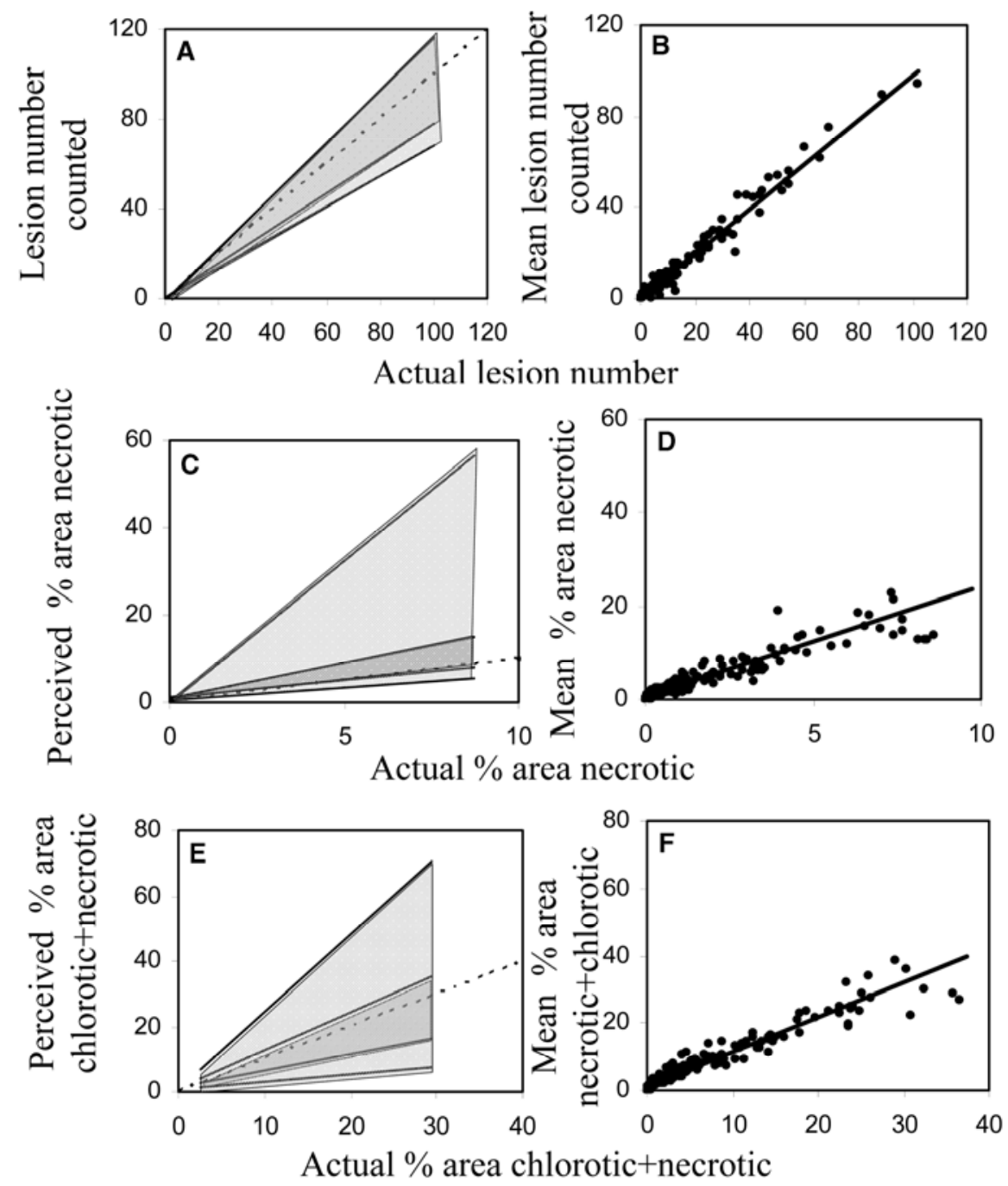

Fig. 3. Distribution of regression analyses of true disease magnitude plotted against estimated disease magnitude for $\mathbf{A}$, lesion number, $\mathbf{C}, \%$ area necrotic, and $\mathbf{E}, \%$ area chlorotic+necrotic for 28 raters. Dark shading shows plant pathologist estimate range; pale shading shows non-plant pathologist range, and dotted line represents line of concordance. Mean data are plotted in $\mathbf{B}, \mathbf{D}$, and $\mathbf{F}$, respectively. For lesion number, $y=a+b \mathrm{LN}$, for $\%$ area necrotic and for $\%$ area chlorotic+necrotic, $y=a+b A+c \mathrm{LN}$. Relationship between true lesion number and true area infected for $\%$ area necrotic was $y=0.113 x$, and for $\%$ area chlorotic+necrotic was $y=0.457 x$. Regressions were drawn assuming number of lesions was 10 per $1.1 \%$ area infected, and 60 per $6.8 \%$ area infected, and for $\%$ chlorotic+necrotic was 10 per $4.6 \%$ area infected and 60 per $27.4 \%$ area infected, respectively. Zero values were not included in these models. Parameters of individual regression solutions and models are given in Tables 2 to 4 .
The absolute error (estimate minus true disease) and relative error (absolute error $\div$ true severity $\times 100$ ) were calculated for the mean estimate at each true severity (or lesion number) to explore how true disease severity was related to error.

\section{RESULTS}

The mean, minimum, and maximum data for each of the raters provide an overview of the characteristics of assessment in relation to the true data (Table 1). The mean true LN by image analysis was 12.3 (range 0 to 102 ), for $\% \mathrm{~N} 1.6 \%$ (range 0 to $8.6 \%$ ) and for $\% \mathrm{CN} 6.6 \%$ (range 0 to $36.7 \%$ ). The mean rater $\mathrm{LN}$ was relatively consistent (9.0 to 13.6), with the rater mean of $\% \mathrm{~N}(1.4$ to $9.7 \%)$ and $\% \mathrm{CN}(2.0$ to $15.7 \%$ ) being less good. The range of data estimates by raters for the three variables also shows LN to be most consistent (range 0 to 117$), \% \mathrm{~N}$ the least consistent (0 to $70 \%$ ), and $\% \mathrm{CN}$ (0 to $90 \%$ ) compared to the ranges for the true data ( 0 to 102,0 to $8.6 \%$, and 0 to $36.7 \%$, respectively). The highest mean estimate of lesion number was made by rater $8(13.6)$, of $\% \mathrm{~N}$ by rater $25(9.8 \%)$, and of \% CN also by rater 25 $(15.7 \%)$. The lowest mean estimate of lesion number was made by rater $7(9.0)$, of $\% \mathrm{~N}$ by rater $13(1.4 \%)$, and of $\% \mathrm{CN}$ also by rater $13(2.0 \%)$.

The frequency distributions of both the true values and the estimates for the 28 raters are variable for $\mathrm{LN}$, but both $\% \mathrm{~N}$ and $\% \mathrm{CN}$ show a tendency to rate disease as more severe than it actually was, with more leaves rated in the higher disease severity categories compared to the true disease (Fig. 1). Among raters there was a variable tendency to over- or underestimate lesion number, but this was relatively mild, and most raters got at least $30 \%$ of the assessments correct (Fig. 2A). In contrast, estimates of $\% \mathrm{~N}$ showed that virtually all raters drastically overestimated disease over the range of true disease, with only raters 13 and 22 showing a tendency to underestimate (Fig. 2B). Among raters there was a lesser tendency to overestimate disease for $\% \mathrm{CN}$, although raters 13 and 22 also underestimated $\% \mathrm{CN}$ to a greater degree (Fig. 2C). Overall, some raters (e.g., raters 1 and 14) had almost equal over- and underestimation of \% $\mathrm{CN}$.

Counts of LN were described by single factor linear regression. The regression analysis (Table 2, Fig. 3A) showed that of the 28 raters, the coefficient of determination for 27 of them exceeded 0.90 (all 28, $r^{2}=0.85$ to 0.98 ). The coefficient of variation for the regression was variable depending on rater $(C V=20.1$ to 54.3$)$. The Breusch-Pagan test showed all raters estimates, and the mean values were heteroscedastic. Agreement measured with Lin's concordance correlation coefficient, $\rho_{c}$ (Fig. 4), was good (0.88 to 0.99). The components of accuracy, $v$ (slope) and $\mu$ (height or location), ranged from 0.72 to 
1.19 and from -0.24 to 0.07 , respectively, suggesting some loss of accuracy with some raters due to slope and height shifts, but the bias correction factor, $C_{b}$, was consistently high $\left(C_{b}=0.92\right.$ to 1.00$)$, showing overall good accuracy. Precision was generally good for all raters and the mean value ( $r=0.92$ to 0.99$)$. The mean estimate of LN from all 28 raters (Fig. 3B) had no scale shift $(v=1.00)$ and a negligible height shift $\left(\mu=0.03 ; C_{b}=1.00, \rho_{c}=\right.$ 0.99 ), demonstrating how the mean estimated values were in excellent agreement with the true data.

A two-factor model best described estimates of $\% \mathrm{~N}$ and $\% \mathrm{CN}$, which incorporated the effect of true percent area infected and true LN. For most raters, LN had a significant effect on estimates of the area infected (Tables 3 and 4, Fig. 3C and E). The coefficients of determination $\left(r^{2}\right)$ were consistently better when incorporating lesion number into the model, ranging from 0.46 to 0.94 for $\% \mathrm{~N}$ and 0.66 to 0.94 for $\% \mathrm{CN}$. Five raters $(1,18,23,27$, and 28) were not apparently affected by LN in estimates of $\% \mathrm{~N}$, and six raters $(3,18,23$, 24,27 , and 28) in estimates of $\% \mathrm{CN}$. The coefficient of variation for the regression tended to be lower for estimates of $\% \mathrm{CN}$ $(C V=32.6$ to 79.0$)$ compared to $\% \mathrm{~N}(C V$ $=35.1$ to 115.0 ). For $\% \mathrm{~N}$, estimates by all but one rater (24) were heteroscedastic. All rater estimates of \% $\mathrm{CN}$ were heteroscedastic. Statistics from Lin's concordance cor-
Table 3. Linear regression of true vs. estimated \% leaf area necrotic for 28 raters estimates of citrus canker severity on 200 grapefruit leaves ${ }^{\mathrm{a}}$

\begin{tabular}{|c|c|c|c|c|c|c|}
\hline Rater & $a$ & $b$ & $c$ & $r^{2}$ & $C V$ & $\begin{array}{c}\text { B-P test } \\
(P>\text { Chisq })\end{array}$ \\
\hline Rater 1 pp & $1.06^{* * *}$ & $0.69 * * *$ & 0.01 & 0.76 & 37.0 & $37.3,<0.001$ \\
\hline Rater 2 pp & $0.87 * * *$ & $1.18^{* * * *}$ & $0.05^{* * *}$ & 0.78 & 48.8 & $60.1,<0.001$ \\
\hline Rater 3 pp & $0.63^{* * *}$ & $0.85^{* * *}$ & $0.03 * * *$ & 0.82 & 41.2 & $35.3,<0.001$ \\
\hline Rater 4 pp & 0.14 & $0.84 * * *$ & $0.07 * *$ & 0.50 & 115.0 & $14.4,<0.001$ \\
\hline Rater 5 & $0.97 * *$ & $2.74 * * *$ & $0.27 * * *$ & 0.86 & 44.4 & $76.2,<0.001$ \\
\hline Rater 6 & -0.53 & $0.74 * * *$ & 0.30 *** & 0.73 & 82.4 & $33.9,<0.001$ \\
\hline Rater 7 & $0.83 * * *$ & $0.71 * * *$ & $0.10 * * *$ & 0.76 & 52.3 & $36.9,<0.001$ \\
\hline Rater 8 & -0.14 & $0.99 * * *$ & $0.24 * * *$ & 0.77 & 70.3 & $27.7,<0.001$ \\
\hline Rater 9 & $0.64 * *$ & $1.06 * * *$ & $0.14 * * *$ & 0.78 & 55.5 & $61.8,<0.001$ \\
\hline Rater 10 & -0.54 & $1.29 * * *$ & $0.30 * * *$ & 0.78 & 73.2 & $73.2,<0.001$ \\
\hline Rater 11 & $0.65^{* * *}$ & $0.81^{* * *}$ & $0.05^{* * *}$ & 0.78 & 48.4 & $24.8,<0.001$ \\
\hline Rater 12 & $1.62 * * *$ & $1.26^{* * *}$ & $0.29 * * *$ & 0.78 & 52.0 & $57.7,<0.001$ \\
\hline Rater 13 & $0.67 * * *$ & $0.18^{* * *}$ & $0.04 * * *$ & 0.58 & 55.6 & $14.9,<0.001$ \\
\hline Rater 14 & 0.06 & $0.78 * * *$ & $0.09 * * *$ & 0.78 & 63.9 & $52.5,<0.001$ \\
\hline Rater 15 & $0.93 * * *$ & $0.66^{* * *}$ & $0.02 * *$ & 0.73 & 43.6 & $74.2,<0.001$ \\
\hline Rater 16 & $0.39^{*}$ & $1.23 * * *$ & $0.10^{* * *}$ & 0.83 & 48.9 & $16.1,<0.001$ \\
\hline Rater 17 & 0.43 & $2.39 * * *$ & $0.44 * * *$ & 0.83 & 54.0 & $50.8,<0.001$ \\
\hline Rater 18 & $1.90 * * *$ & $0.93^{* * *}$ & 0.02 & 0.59 & 48.6 & $50.9,<0.001$ \\
\hline Rater 19 & $0.76^{* * *}$ & $1.88 * * *$ & $0.21 * * *$ & 0.90 & 35.1 & $67.3,<0.001$ \\
\hline Rater 20 & $1.26^{* * * *}$ & $1.69^{* * * *}$ & $0.03 *$ & 0.82 & 41.3 & $31.9,<0.001$ \\
\hline Rater 21 & 0.49 & $1.71 * * *$ & $0.24 * * *$ & 0.86 & 46.7 & $82.0,<0.001$ \\
\hline Rater 22 & $-0.45 * * *$ & $-0.10^{*}$ & $0.20 * * *$ & 0.94 & 42.4 & $39.0,<0.001$ \\
\hline Rater 23 & $1.69 * * *$ & $1.00 * * *$ & 0.03 & 0.60 & 54.6 & $32.8,<0.001$ \\
\hline Rater 24 pp & $0.58 * * *$ & $0.78 * * *$ & $0.07 * * *$ & 0.70 & 63.4 & $5.3, \mathrm{NS}$ \\
\hline Rater 25 & -0.23 & $4.01 * * *$ & $0.28 * * *$ & 0.84 & 53.8 & $47.7,<0.001$ \\
\hline Rater 26 & $0.61 * * *$ & $0.81 * * *$ & $0.09 * * *$ & 0.84 & 42.6 & $31.2,<0.001$ \\
\hline Rater 27 & $0.55^{* * * *}$ & $0.75^{* * *}$ & 0.02 & 0.62 & 69.2 & $38.0,<0.001$ \\
\hline Rater 28 & $1.08 * * *$ & $1.22 * * *$ & -0.01 & 0.46 & 86.8 & $9.0,<0.05$ \\
\hline Mean & $0.62 * * *$ & $1.19 * * *$ & $0.13 * * *$ & 0.94 & 25.4 & $48.6,<0.001$ \\
\hline
\end{tabular}

${ }^{a}$ Linear regression where the model $y=a+b A+c L N$ represents \% leaf area necrotic, where $A$ is the true \% leaf area necrotic, $L N$ the true lesion number, $a, b$, and $c$ are constants parameters. Actual lesion number/area measured with image analysis, mean $=$ average of all 28 raters. $r^{2}=$ coefficient of determination, $C V=$ coefficient of variation of the regression. ***, $P<0.001 ; * *, P<0.01 ; *, P<$ 0.05 . Breusch-Pagan (B-P) test checks for heteroscedasticity. ${ }^{\mathrm{pp}}$ indicates trained plant pathologists.
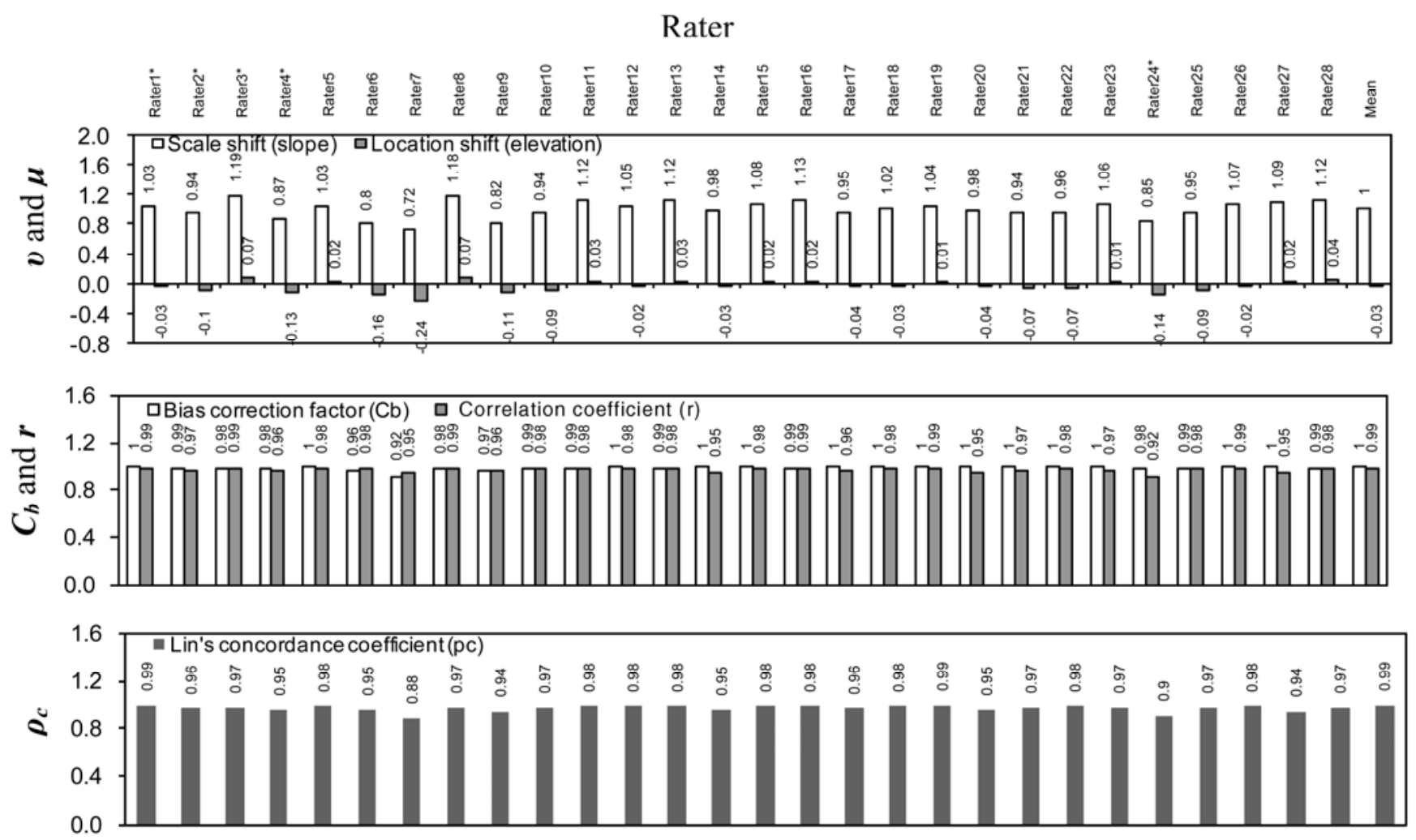

Fig. 4. Lin's concordance correlation analysis of assessor counts of lesion numbers on 200 grapefruit leaves assessed by 28 raters. $v=$ slope shift $(1=$ no bias between $X$ and $Y$ ) relative to the concordance line; $\mu=$ location, or elevation shift ( $0=$ no bias) relative to the concordance line; $C_{b}=$ bias correction factor ( 1 $=$ no bias $), r=$ correlation coefficient $(1=$ perfect precision $)$, and $\rho_{c}=$ Lin's concordance correlation coefficient $(1=$ perfect concordance correlation). $*$ indicates trained plant pathologists. 
relation coefficient showed poorer agreement with true values for estimates of $\% \mathrm{~N}$ compared to \%CN (Fig. 5A, B, and C). Lin's concordance correlation coefficient ranged from 0.19 to 0.84 for $\% \mathrm{~N}$ and from 0.54 to 0.94 for $\% \mathrm{CN}$. For $\% \mathrm{~N}$, the components of accuracy, $v$ (scale), ranged from 0.65 to 6.62 , and $\mu$ (height), from -0.23 to 1.61, respectively; while for $\% \mathrm{CN}, v$ ranged from 0.26 to 2.45 and $\mu$ from -0.41 to 0.83 , showing loss of accuracy due to scale and location shifts among raters, which was most often more severe for $\% \mathrm{~N}$. Reflecting this tendency, the bias correction factor, $C_{b}$, for $\% \mathrm{~N}$ ranged from 0.21 to 0.98 and for $\% \mathrm{CN}$ from 0.38 to 1.00 . As a measure of precision, rater correlation coefficients for $\% \mathrm{~N}$ ( $r=0.67$ to 0.91$)$ were less good than those for $\% \mathrm{CN}$ ( $r=0.81$ to 0.94). Raters with lower $r$ values were less precise in estimates of area infected, and $r$ values for $\% \mathrm{~N}$ were often, but not always, lower compared to $\% \mathrm{CN}$ (for example, for $\% \mathrm{~N}$ and $\% \mathrm{CN}$, rater $3 r=0.90,0.89$, rater $4 r=0.69,0.84$, and rater $17 r=0.85$, 0.90 , respectively). Agreement with true values was thus rater dependent with the concordance correlation coefficient, $\rho_{c}$, for $\% \mathrm{~N}$ ranging from 0.19 to 0.84 , and for $\% \mathrm{CN}$ from 0.30 to 0.94 . With the mean estimates of severity based on all 28 raters, the coefficient of determination $\left(r^{2}\right)$ was
0.94 for $\% \mathrm{~N}$ (Table 3, Fig. 3D) and 0.95 for $\% \mathrm{CN}$ (Table 4 , Fig. 3F) with agreement $\left(\rho_{c}\right)$ being 0.55 and 0.96 for $\% \mathrm{~N}$ and $\% \mathrm{CN}$ (Fig. 5), respectively, showing the mean estimates for $\% \mathrm{CN}$ were in better agreement with true values than those of $\% \mathrm{~N}$.

Higher lesion numbers for a given leaf area infected generally resulted in overestimation, and low true disease severity caused greater overestimation for most raters. This was true for both $\% \mathrm{~N}$ and $\% \mathrm{CN}$ (Table 5, Fig. 6A and C). A twofactor model incorporating $\log _{e} A$ and $\log _{e} L N$ best described this relationship and gave higher coefficients of determination compared to other single or two-factor models (for $\% \mathrm{~N} r^{2}=0.03$ to 0.65 and for $\% \mathrm{CN} r^{2}=0.04$ to 0.67 , respectively). Four raters did not appear to be influenced by lesion number in estimations of $\% \mathrm{~N}$ (raters $3,9,24$, and 28 ) or \%CN (raters 1, 9, 24, and 28). Certain raters apparently had fairly constant estimation bias over the severity estimated (Fig. 6B and D), and at least one of the raters tended to overestimate more with increasing lesion number and severity (rater 6).

The variance describes the degree to which the data are "spread out", and the $\log$ variance of the mean data from these rater assessments showed a linear relation-

Table 4. Linear regression of true vs. estimated \% leaf area chlorotic+necrotic for 28 raters estimates of citrus canker severity on 200 grapefruit leaves ${ }^{\mathrm{a}}$

\begin{tabular}{|c|c|c|c|c|c|c|}
\hline Rater & $a$ & $b$ & $c$ & $r^{2}$ & $C V$ & $\begin{array}{c}\text { B-P test } \\
(P>C h i s q)\end{array}$ \\
\hline Rater 1 pp & $1.52 * * *$ & $0.65 * * *$ & $-0.07 * * *$ & 0.80 & 43.6 & $43.0,<0.001$ \\
\hline Rater 2 pp & $1.63^{* * *}$ & $0.54 * * *$ & $0.05^{* *}$ & 0.85 & 36.6 & $51.9,<0.001$ \\
\hline Rater 3 pp & $1.44 * * *$ & $0.66 * * *$ & 0.04 & 0.80 & 47.0 & $36.7,<0.001$ \\
\hline Rater 4 pp & 0.77 & $0.42 * * *$ & $0.34 * * *$ & 0.79 & 57.5 & $30.0,<0.001$ \\
\hline Rater 5 & $4.09 * * *$ & $1.24 * * *$ & $0.29 * * *$ & 0.87 & 34.7 & $38.5,<0.001$ \\
\hline Rater 6 & $-1.33 * * *$ & $0.89 * * *$ & $0.43 * * *$ & 0.89 & 47.4 & $71.9,<0.001$ \\
\hline Rater 7 & $1.09 * * *$ & $0.34 * * *$ & $0.09 * * *$ & 0.79 & 47.6 & $36.1,<0.001$ \\
\hline Rater 8 & -0.47 & $0.82 * * *$ & $0.19 * * *$ & 0.85 & 55.5 & $17.4,<0.001$ \\
\hline Rater 9 & $1.13 * * *$ & $0.50 * * *$ & $0.13^{* * *}$ & 0.80 & 48.9 & $53.5,<0.001$ \\
\hline Rater 10 & -0.18 & $0.50 * * *$ & $0.33^{* * *}$ & 0.72 & 79.0 & $67.0,<0.001$ \\
\hline Rater 11 & $1.05 * * *$ & $0.49 * * *$ & $0.08^{* * *}$ & 0.79 & 49.9 & $19.0,<0.001$ \\
\hline Rater 12 & $2.90 * * *$ & $0.51 * * *$ & $0.34 * * *$ & 0.82 & 41.7 & $58.2,<0.001$ \\
\hline Rater 13 & $0.62 * * *$ & $0.15^{* * *}$ & $0.04 * * *$ & 0.66 & 61.1 & $29.8,<0.001$ \\
\hline Rater 14 & $1.12 * * *$ & $0.54 * * *$ & $0.10^{* * *}$ & 0.87 & 38.5 & $41.0,<0.001$ \\
\hline Rater 15 & 0.49 & $0.75 * * *$ & $0.18 * * *$ & 0.85 & 47.3 & $54.9,<0.001$ \\
\hline Rater 16 & $0.72 *$ & $0.67 * * *$ & $0.16^{* * *}$ & 0.86 & 43.5 & $29.6,<0.001$ \\
\hline Rater 17 & $1.37 *$ & $1.05^{* * *}$ & $0.40^{* * * *}$ & 0.87 & 43.2 & $47.2,<0.001$ \\
\hline Rater 18 & $4.12 * * *$ & $0.49 * * *$ & 0.01 & 0.66 & 38.9 & $10.8,<0.01$ \\
\hline Rater 19 & $1.89 * * *$ & $0.98 * * *$ & $0.40^{* * * *}$ & 0.93 & 29.9 & $52.9,<0.001$ \\
\hline Rater 20 & $3.35^{* * *}$ & $0.94 * * *$ & $0.07 *$ & 0.82 & 38.4 & $40.5,<0.001$ \\
\hline Rater 21 & $0.97 * *$ & $1.01 * * *$ & $0.17 * * *$ & 0.90 & 36.9 & $69.3,<0.001$ \\
\hline Rater 22 & $-0.82 * * *$ & 0.01 & $0.37 * * *$ & 0.94 & 43.4 & $55.6,<0.001$ \\
\hline Rater 23 & $3.76 * * *$ & $0.50 * * *$ & 0.04 & 0.71 & 38.7 & $24.9,<0.001$ \\
\hline Rater 24 pp & $1.24 * * *$ & $0.86^{* * *}$ & -0.03 & 0.90 & 32.6 & $59.8,<0.001$ \\
\hline Rater 25 & 0.63 & $1.76 * * *$ & $0.28 * * *$ & 0.87 & 44.8 & $69.3,<0.001$ \\
\hline Rater 26 & $1.41 * * *$ & $0.65^{* * *}$ & $0.08 * * *$ & 0.86 & 38.3 & $66.5,<0.001$ \\
\hline Rater 27 & $1.00 * * *$ & $0.46 * * *$ & 0.01 & 0.67 & 64.3 & $31.0,<0.001$ \\
\hline Rater 28 & $3.37 * * *$ & $0.80 * * *$ & -0.03 & 0.75 & 41.2 & $53.6,<0.001$ \\
\hline Mean & $1.43 * * *$ & $0.69 * * *$ & $0.15 * * *$ & 0.95 & 22.1 & $83.3,<0.001$ \\
\hline
\end{tabular}

${ }^{a}$ Linear regression where the model $y=a+b A+c L N$ represents \% leaf area chlorotic+necrotic, where $A$ is the true \% leaf area chlorotic+necrotic, $L N$ the true lesion number, and $a, b$, and $c$ are constant parameters. Actual lesion number/area measured with image analysis, mean $=$ average of all 28 raters. $r^{2}=$ coefficient of determination, $C V=$ coefficient of variation of the regression. $* * *, P<0.001$; ${ }^{* *}, P<0.01 ; *, P<0.05$. Breusch-Pagan (B-P) test checks for heteroscedasticity. ${ }^{\mathrm{pP}}$ indicates trained plant pathologists. ship with $\log$ true disease (Fig. 7) for lesion number $\left(r^{2}=0.71\right), \% \mathrm{~N}\left(r^{2}=0.85\right)$, and $\% \mathrm{CN}\left(r^{2}=0.88\right)$. The variance of the mean estimate increased as true disease increases over the range in this study. A $\log -\log$ plot of this type is a linearization of the true relationship which is curvilinear between magnitude of the true disease in this study. Furthermore, direct estimation of the area showing symptoms led to the phenomenon of individuals tending to prefer the estimate of disease above about $10 \%$ being rated to the nearest 5 or $10 \%$ presumed area infected, which is reflected by the frequency of severity estimates falling on $10,15,20,25,30,35$, etc. percent infected for $\% \mathrm{~N}$ and $\% \mathrm{CN}$ (Fig. $8 \mathrm{~B}$ and $\mathrm{C}$ ). Below $10 \%$, raters appeared comfortable estimating to the nearest $1 \%$. This knotting of estimates was not noticeable in counts of LN (Fig. 8A).

The $t$ test found no effect of gender on any of the variables tested. Correlation analysis found no significant association between the estimates of mean disease, standard deviation, variance, scale $(v)$, or locational $(\mu)$ shifts, $C_{b}, \rho_{c}$, or the correlation coefficient between true and estimated severity for each rater versus rater age, years of education, time worked as a surveyor, number of days training in canker identification, recency of canker find, days of other plant pest and disease identification and assessment training, or CCEP test scores in 2004, 2006, and 2007, or the time taken to assess all 200 images. Significant association was found between TS2003 and $\mathrm{LN}-\mu(0.54,<0.04), \mathrm{LN}-C_{b} \quad(0.57$, $<0.03)$, and $\mathrm{LN}-\rho_{c}(0.60,<0.02)$, TS2005 and $\mathrm{LN}-\rho_{c}(0.65,<0.005)$, and Average Score and LN-mean $(0.47,<0.05), \mathrm{LN}-\mu$ $(0.50,<0.03), \mathrm{LN}-C_{b}(0.59,<0.01), \mathrm{LN}-\rho_{c}$ $(0.47,<0.05), \% \mathrm{CN}-C_{b}(0.47,<0.05)$, and $\mathrm{NC}-\rho_{c}(0.49,<0.04)$.

GLM analysis to test whether rating was the same by PPs and NPPs showed LN, $\% \mathrm{~N}$, and $\% \mathrm{CN}$ were rated differently by the two groups (Table 6). Both PPs and NPPs gave reasonably precise estimates of lesion number $\left(r^{2}>0.92\right.$ and 0.94 , respectively), but for estimates of $\% \mathrm{~N}$ and $\% \mathrm{CN}$, the PPs were consistently more precise $\left(\% \mathrm{~N}\right.$ and $\% \mathrm{CN}, r^{2}=0.61$ and 0.73 , respectively) compared to NPPs $(\% \mathrm{~N}$ and $\% \mathrm{CN}$, $r^{2}=0.45$ and 0.58 , respectively). Estimates of the intercept and slope showed that the slope for estimates of $\% \mathrm{~N}$ by PPs (1.18) was closer to 1 compared to that of NPPs (2.27). However, for estimates of $\% \mathrm{CN}$, the slope for NPPs was 0.97, compared to 0.74 for the PPs.

The association among symptom types (Fig. 9) measured by image analysis showed that $\mathrm{LN}$ versus $\% \mathrm{~N}$ was least strong $\left(r^{2}=0.68\right)$, followed by $\mathrm{LN}$ versus $\% \mathrm{CN}\left(r^{2}=0.73\right)$, and best between $\% \mathrm{~N}$ and $\% \mathrm{CN}\left(r^{2}=0.91\right)$. In general agreement with this, there was a relatively poor association between estimates of $\mathrm{LN}$ and $\% \mathrm{~N}$ for most raters $\left(r^{2}=0.31\right.$ to 0.81$)$, except 
rater 22 who showed a good association between estimates of $\mathrm{LN}$ and $\% \mathrm{~N}(0.97)$. Similarly, between $\mathrm{LN}$ and $\% \mathrm{CN}$, most raters had coefficients of determination from 0.47 to 0.86 , except rater 22 who again showed a good association between $\mathrm{LN}$ and $\% \mathrm{CN}\left(r^{2}=0.96\right)$. The relationship between estimates of symptoms of $\% \mathrm{~N}$ and $\% \mathrm{CN}$ tended to be better and certain raters showed a good association, with 12 raters having an $r^{2}>0.90$ (overall range 0.48 to 0.99). The relationship among symptom types depended on ability of a rater with each symptom. Rater 19 overestimated both $\% \mathrm{~N}$ and $\% \mathrm{CN}$, resulting in a strong

A $\%$ area necrotic

Rater
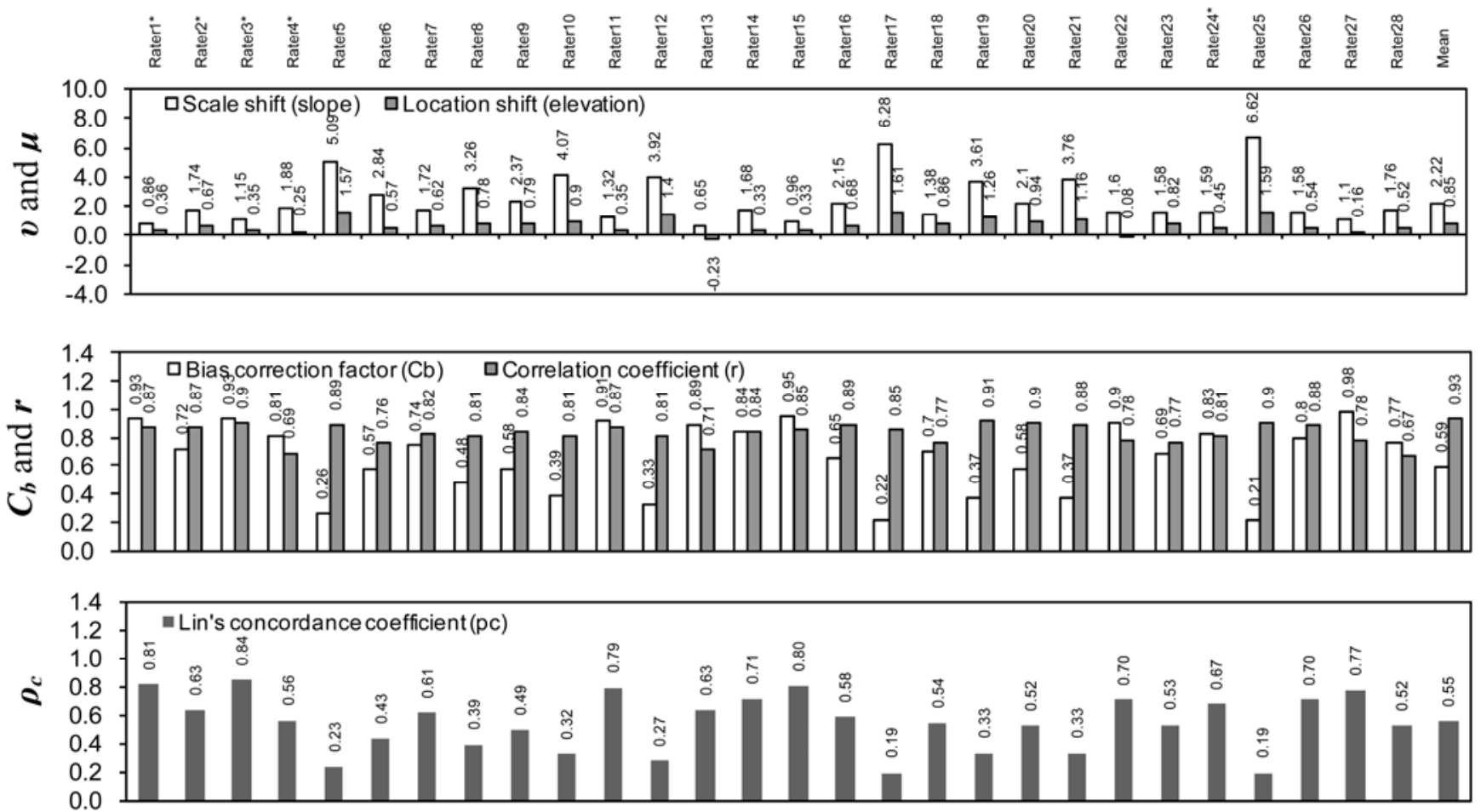

B $\%$ area chlorotic + necrotic
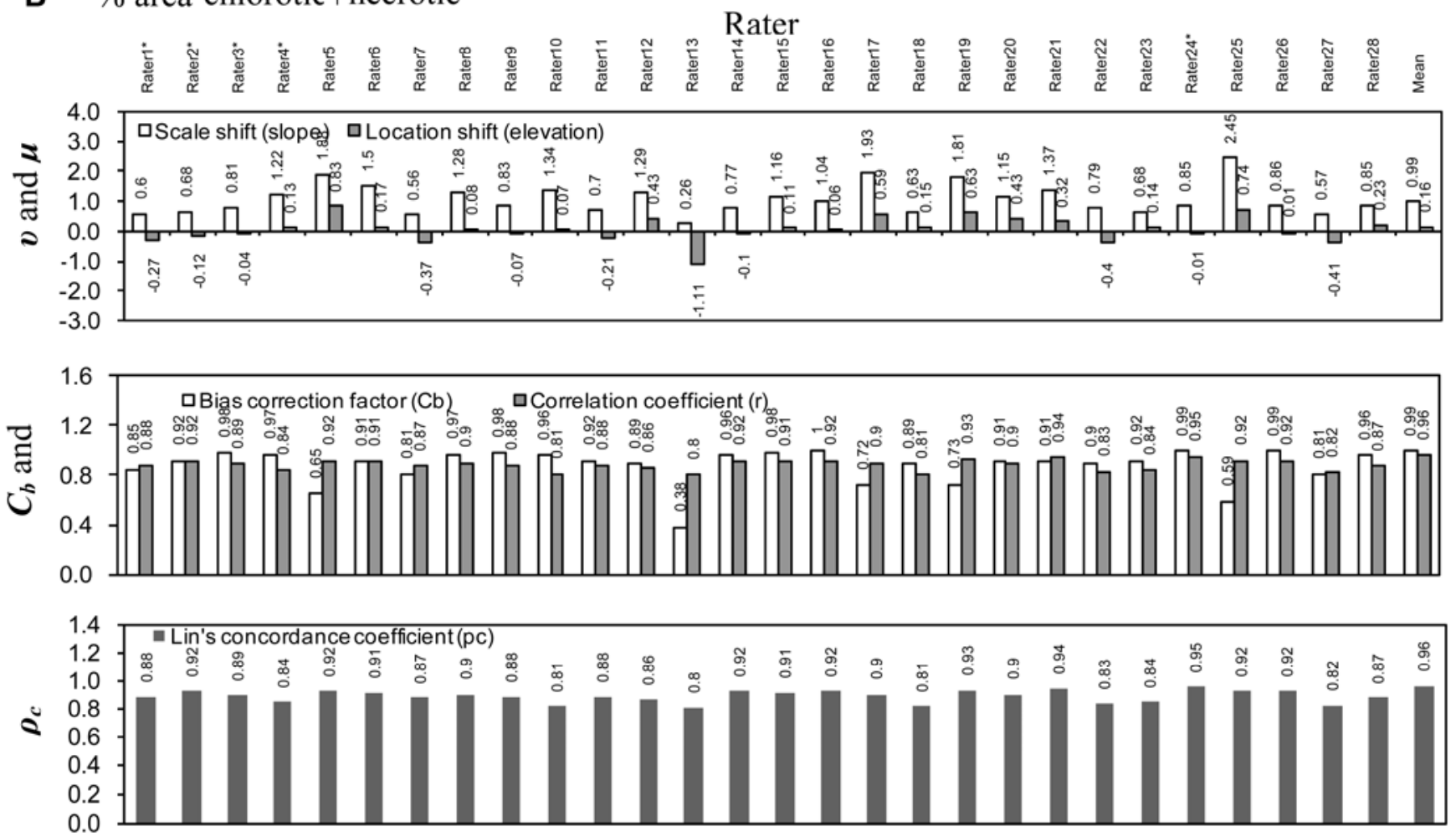

Fig. 5. Lin's concordance correlation analysis for rater estimates of $\mathbf{A}$, $\%$ area necrotic, and $\mathbf{B}$, \% area chlorotic+necrotic on 200 grapefruit leaves assessed by 28 raters. $v=$ slope shift $(1=$ no bias between $X$ and $Y)$ relative to concordance line; $\mu=$ location, or elevation shift $(0=$ no bias $)$ relative to concordance line; $C_{b}=$ bias correction factor $(1=$ no bias $), r=$ correlation coefficient $(1=$ perfect precision $)$, and $\rho_{c}=$ Lin's concordance correlation coefficient $(1=$ perfect concordance correlation). * indicates trained plant pathologists. 
coefficient of determination between these estimates $\left(r^{2}=0.96\right)$. On the other hand, rater 1 showed a much greater tendency to overestimate $\mathrm{N}$ compared to $\mathrm{CN}$, and this resulted in a relatively poor relationship between estimates of the two symptom types $\left(r^{2}=0.65\right)$. Thus, relationships among estimates of components of disease symptoms can reflect the rater's ability and not necessarily the actual relationship defined by comparing measurement of true disease taken using a system like image analysis.

The absolute error for mean lesion number differed up to $+/-15$ lesions, but the majority of mean counts were within 5 lesions of the true count (Fig. 10A). The absolute error increased only slowly with increasing lesion number. However, the relative error was much greater (up to approximately $100 \%$ ) with some counts of low lesion numbers. The relative error rapidly declined with increasing true lesion number and showed no noticeable bias toward under- or overestimation. The absolute error of the $\% \mathrm{~N}$ (Fig. 10B) increased up to the maximum area infected $(8 \%)$. The relative error was mostly positive and dramatic at severity $<4 \%$ (up to approximately $700 \%$ overestimation), and it remained a positive relative error up to $8 \%$, in keeping with the tendency to overestimate disease at low severity. The $\% \mathrm{CN}$ (Fig. 10C) showed an increase in absolute
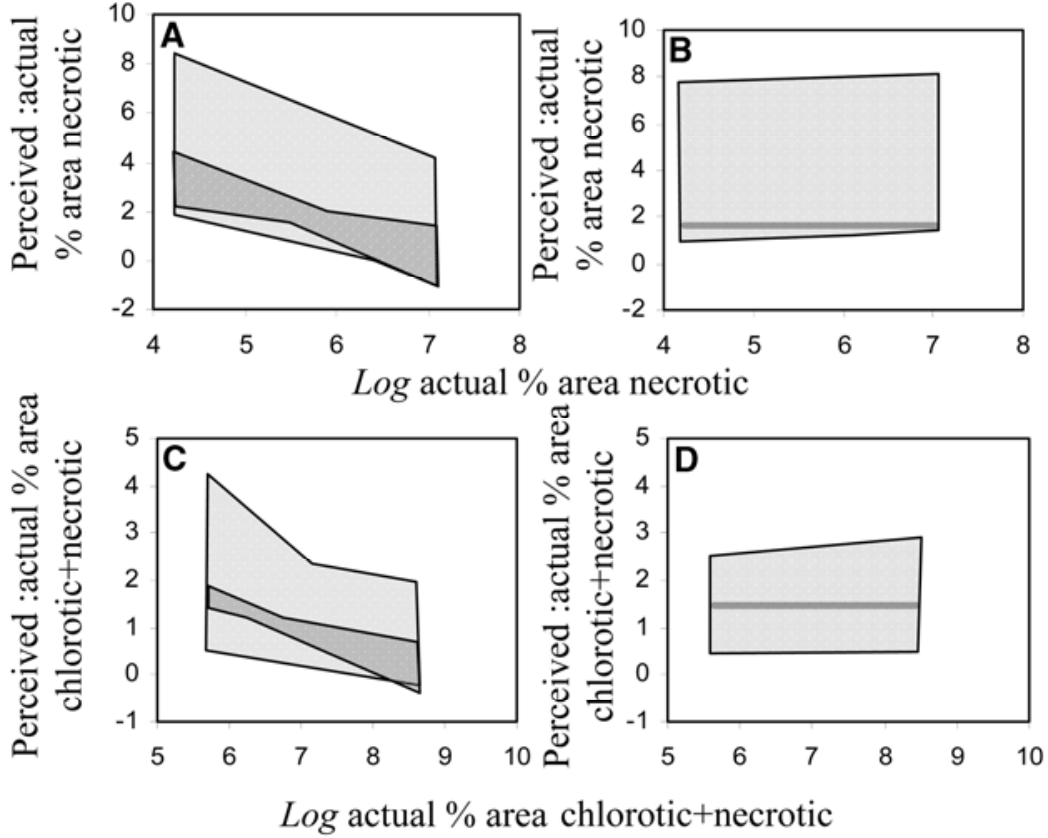

Fig. 6. Distribution of regression analyses of the relationship between ratio of perceived $\%$ area disease:true $\%$ area disease against natural $\log$ of true area diseased for $\%$ area necrotic $(\mathbf{A}, \mathbf{B})$ and $\%$ area chlorotic+necrotic (C, D). Dark shading shows plant pathologist estimate range; pale shading shows non-plant pathologist range. $\mathbf{A}$ and $\mathbf{C}$ show raters with an inverse relationship between overestimation and true disease, and $\mathbf{B}$ and $\mathbf{D}$ show the raters who had constant or increasing overestimation with increased true disease. For $\%$ area necrotic and \% area chlorotic+necrotic, $y=a+b A+c \mathrm{LN}$. Relationship between true lesion number and true area infected for \% area necrotic, $y=0.113 x$, and for $\%$ area chlorotic+necrotic, $y=0.457 x$, respectively. Regressions were drawn assuming number of lesion for $\%$ area necrotic was 10 lesions per $1.1 \%$, and 60 per $6.8 \%$ area infected, and for $\%$ area chlorotic+necrotic was 10 lesions per $4.63 \%$ area and 60 per $27.4 \%$ area, respectively. Zero values were not included in these models. Parameters of regression solutions and models are given in Table 5.

Table 5. Regression analysis of the relationship between the ratio of the perceived disease area:true disease area and true disease area for symptoms of citrus canker on 200 grapefruit leaves for 28 raters for $\%$ area necrotic and $\%$ area chlorotic + necrotic $^{\mathrm{a}}$

\begin{tabular}{|c|c|c|c|c|c|c|c|c|}
\hline \multirow[b]{2}{*}{ Rater } & \multicolumn{4}{|c|}{$\%$ area necrotic } & \multicolumn{4}{|c|}{$\%$ area chlorotic+necrotic } \\
\hline & $a$ & $b$ & $c$ & $r^{2}$ & $a$ & $b$ & $c$ & $r^{2}$ \\
\hline Rater 1 pp & $9.03 * * *$ & $-2.29 * * *$ & $0.65^{* * *}$ & 0.65 & $4.60 * * *$ & $-0.67 * * *$ & 0.10 & 0.61 \\
\hline Rater 2 pp & $7.47 * * *$ & $-2.56 * * *$ & $1.16 * * *$ & 0.63 & $4.33 * * *$ & $-0.90 * * *$ & $0.37 * * *$ & 0.63 \\
\hline Rater 3 pp & $4.42 * * *$ & $-0.33 * *$ & -0.15 & 0.20 & $3.14 * * *$ & $-0.15^{*}$ & $-0.15^{*}$ & 0.30 \\
\hline Rater 4 pp & 0.61 & $-0.54 * * *$ & $0.52 * * *$ & 0.17 & $0.93^{*}$ & $-0.71 * * *$ & $0.70^{* * *}$ & 0.23 \\
\hline Rater 5 & $8.61 * * *$ & $-3.85^{* * *}$ & $2.43 * * *$ & 0.31 & $11.42 * * *$ & $-2.14 * * *$ & $0.77 * *$ & 0.41 \\
\hline Rater 6 & $-1.27 *$ & $-1.06 * * *$ & $1.46^{* * *}$ & 0.18 & -0.12 & $-0.53 * * *$ & $0.71 * * *$ & 0.38 \\
\hline Rater 7 & $6.40 * * *$ & $-2.58 * * *$ & $1.30 * * *$ & 0.52 & $2.92 * * *$ & $-0.78 * * *$ & $0.42 * * *$ & 0.49 \\
\hline Rater 8 & $2.52 * *$ & $-2.09 * * *$ & $1.55^{* * *}$ & 0.30 & $1.76^{* * *}$ & $-0.64 * * *$ & $0.49 * * *$ & 0.28 \\
\hline Rater 9 & $4.83 * * *$ & $-0.76^{*}$ & 0.27 & 0.05 & $2.23 * * *$ & -0.06 & -0.11 & 0.04 \\
\hline Rater 10 & $4.03 * * *$ & $-2.68 * * *$ & $1.84 * * *$ & 0.46 & $2.01 * * *$ & $-0.70 * * *$ & $0.52 * * *$ & 0.32 \\
\hline Rater 11 & $3.97 * * *$ & $-1.38 * * *$ & $0.69 * * *$ & 0.45 & $2.21 * * *$ & $-0.63 * * *$ & $0.40 * * *$ & 0.48 \\
\hline Rater 12 & $8.18 * * *$ & $-3.59 * * *$ & $2.20 * * *$ & 0.47 & $5.57 * * *$ & $-1.53 * * *$ & $0.90 * * *$ & 0.57 \\
\hline Rater 13 & $4.14 * * *$ & $-1.29 * * *$ & $0.49 * * *$ & 0.61 & $1.89 * * *$ & $-0.38 * * *$ & $0.14 * *$ & 0.39 \\
\hline Rater 14 & $3.16^{* * *}$ & $-1.26 * * *$ & $0.70 * * *$ & 0.38 & $3.35 * * *$ & $-0.75 * * *$ & $0.36^{* * *}$ & 0.53 \\
\hline Rater 15 & $8.10 * * *$ & $-2.29 * * *$ & $0.77 * * *$ & 0.63 & $2.94 * * *$ & $-0.63 * * *$ & $0.34 * * *$ & 0.35 \\
\hline Rater 16 & $3.94 * * *$ & $-1.80 * * *$ & $1.10 * * *$ & 0.31 & $3.05 * * *$ & $-0.87 * * *$ & $0.55^{* * *} *$ & 0.41 \\
\hline Rater 17 & -1.08 & $-3.43 * * *$ & $3.54 * * *$ & 0.33 & $3.06 * * *$ & $-1.67 * * *$ & $1.41 * * *$ & 0.33 \\
\hline Rater 18 & $12.72 * * *$ & $-2.89 * * *$ & $0.73 * *$ & 0.63 & $6.91 * * *$ & $-1.28 * * *$ & $0.42 * * *$ & 0.67 \\
\hline Rater 19 & $7.63 * * *$ & $-2.90 * * *$ & $1.65^{* * *}$ & 0.51 & $8.08 * * *$ & $-1.91 * * *$ & $0.95 * * *$ & 0.63 \\
\hline Rater 20 & $7.81 * * *$ & $-2.48 * * *$ & $1.15^{* * *}$ & 0.52 & $5.47 * * *$ & $-1.12 * * *$ & $0.52 * * *$ & 0.38 \\
\hline Rater 21 & $2.52 * *$ & $-2.54 * * *$ & $2.06 * * *$ & 0.41 & $1.93 * * *$ & $-0.74 * * *$ & $0.63 * * *$ & 0.35 \\
\hline Rater 22 & $-2.16 * *$ & $-1.12 * * *$ & $1.27 * * *$ & 0.20 & 0.02 & $-0.77 * * *$ & $0.79 * * *$ & 0.17 \\
\hline Rater 23 & $12.39 * * *$ & $-2.91 * * *$ & $0.79 * *$ & 0.59 & $6.57 * * *$ & $-1.20 * * *$ & $0.39 * * *$ & 0.63 \\
\hline Rater 24 pp & $3.41 * *$ & -0.49 & 0.15 & 0.03 & $2.67 * * *$ & $-0.34 * * *$ & 0.09 & 0.31 \\
\hline Rater 25 & 1.13 & $-2.49 * * *$ & $2.50 * * *$ & 0.23 & 1.08 & $-0.80 * * *$ & $0.94 * * *$ & 0.16 \\
\hline Rater 26 & $3.86^{* * *}$ & $-1.05 * * *$ & $0.52 * * *$ & 0.35 & $2.64 * * *$ & $-0.47 * * *$ & $0.23^{* *}$ & 0.27 \\
\hline Rater 27 & $4.42 * * *$ & $-1.34 * * *$ & $0.55 * * *$ & 0.53 & $3.21 * * *$ & $-0.74 * * *$ & $0.33^{* * * *}$ & 0.50 \\
\hline Rater 28 & $9.38 * * *$ & $-1.11 * * *$ & -0.20 & 0.51 & $6.87 * * *$ & $-0.64 * * *$ & -0.16 & 0.57 \\
\hline Mean & $4.58 * * *$ & $-1.83 * * *$ & $1.08 * * *$ & 0.60 & $3.26 * * *$ & $-0.71 * * *$ & $0.38 * * *$ & 0.55 \\
\hline
\end{tabular}

a Regression analysis where the model $y=a+b A+c L N$ represents \% leaf area infected, where $A$ is the true \% leaf area infected, $L N$ the true lesion number, and $a, b$, and $c$ are constant parameters. Actual lesion number/area measured with image analysis, mean $=$ average of all 28 raters. $r^{2}=$ coefficient of determination, $C V=$ coefficient of variation of the regression. ${ }^{* * *}, P<0.001 ; * *, P<0.01 ; *, P<0.05$. ${ }^{\text {PP }}$ indicates trained plant pathologists. 
error to approximately $8 \%$ area infected (maximum true area infected was $37 \%$ ), and although the error increased, it became more balanced around zero at true severity $>8 \%$. Like $\% \mathrm{~N}, \% \mathrm{CN}$ tended to be overestimated at severity $<8 \%$. The relative error for $\% \mathrm{CN}$ was almost exclusively positive and dramatic at severity $<8 \%$ (up to approximately $570 \%$ ), but at severity $>10 \%$ it was relatively small with both over- and underestimates.

\section{DISCUSSION}

The estimates of disease by raters were all direct and unaided. Despite the assessors being familiar with the symptoms of citrus canker, they showed a wide range of ability to estimate severity. However, the only parameters related to ability to assess disease were some measures of the CCEP identification test score. There was no other association between the various characteristics of the assessors and their ability to assess disease. Training and the use of standard area diagrams are known to improve ability to assess disease, as is time taken to assess the disease $(3,31,33,35)$. Higher CCEP test scores might reflect an innate visual ability of those raters, which helped with disease assessment. Otherwise age, gender, years of experience, time taken to complete assessment, or any other factors did not appear to affect error or ability to assess disease accurately and precisely. The ability to directly estimate disease severity may be a subtle trait re- lated to inherent visual competencies that vary from individual to individual and not necessarily related to factors chosen in this study.

PPs and NPPs differed in assessment of all three symptom types. Although different, the parameters showed both groups counted lesions accurately: straightforward counts are likely to be much easier than estimates of area infected, as previously shown by Bock et al. $(5,6)$. Differences between experienced and inexperienced raters have been observed (28), and PPs were more accurate and precise estimating $\% \mathrm{~N}$ compared to NPPs but less accurate (although more precise) estimating \% CN (Table 6). Trained PPs might be more consistent and show a lesser tendency to over-

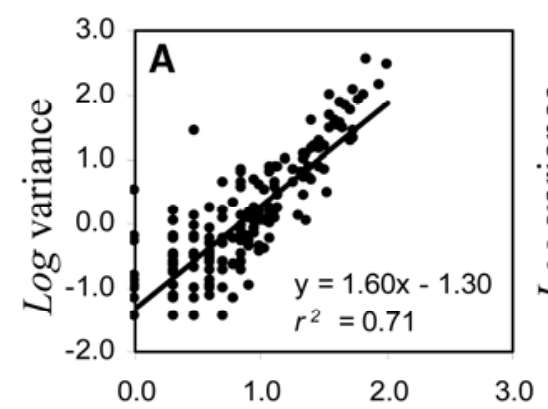

Log true lesion number

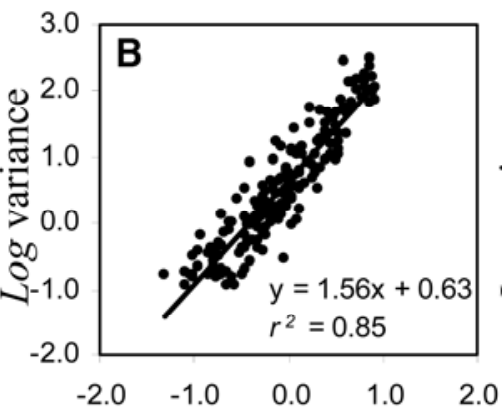

$\log$ true $\%$ area necrotic

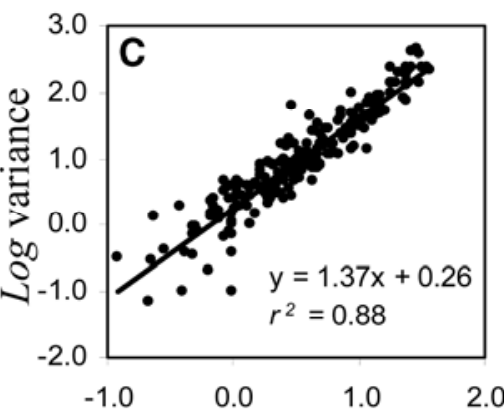

$\log$ true $\%$ area chlorotic+necrotic

Fig. 7. Relationship between $\mathbf{A}, \log$ variance of rater counts of lesion number and log true lesion count, $\mathbf{B}$, log variance of rater estimates of $\%$ area necrotic and $\log$ true $\%$ area necrotic, and $\mathbf{C}, \log$ variance of rater estimates of $\%$ area chlorotic+necrotic and log true $\%$ area chlorotic+necrotic. Variances of rater estimates are each based on a total of 28 individual rater estimates of the severity of disease on each of 200 leaves.
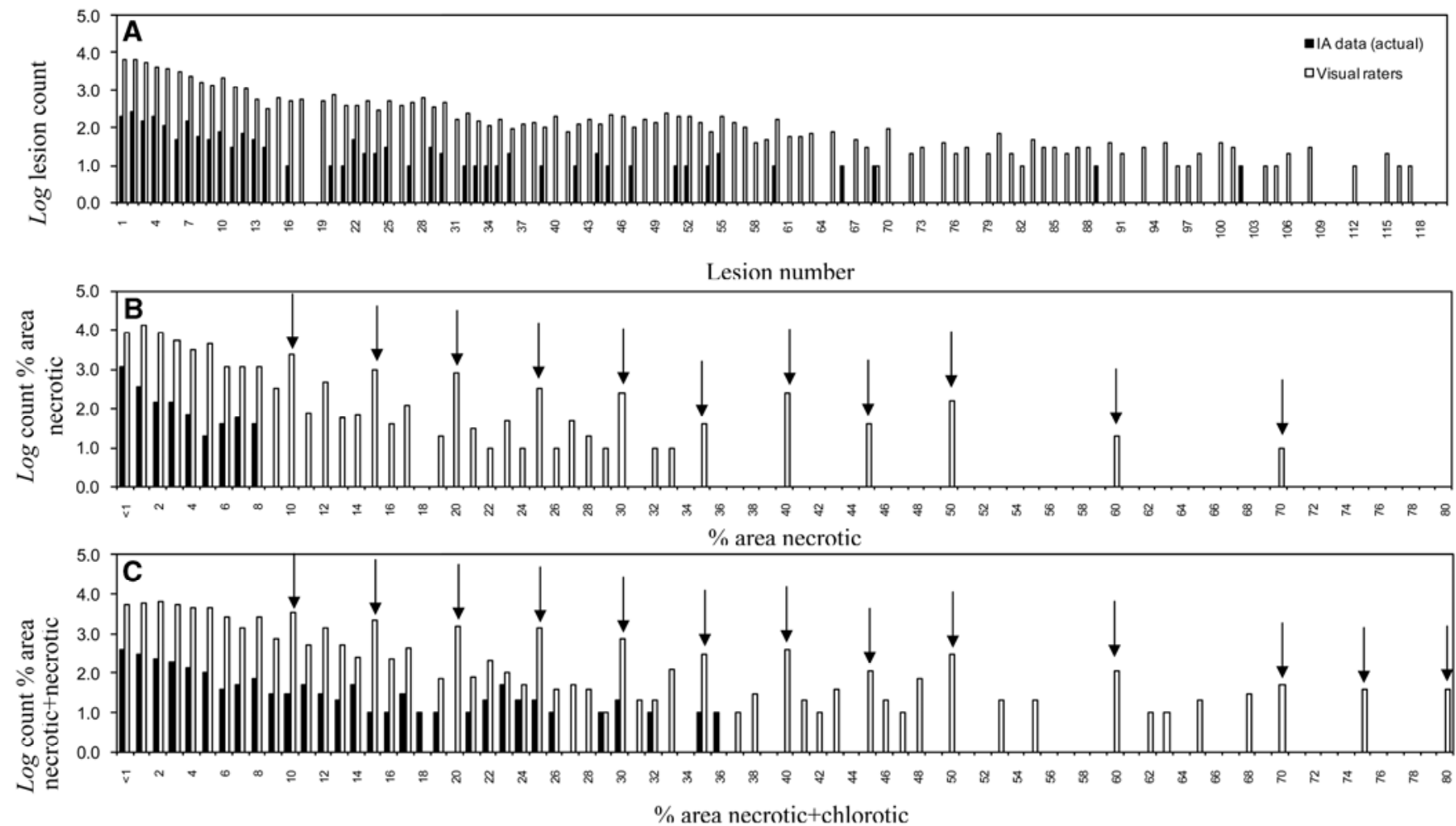

Fig. 8. Frequency of knots with 28 raters assessing 200 leaves for A, lesion number, B, \% area necrotic, and C, \% area chlorotic+necrotic. Arrows mark "knots" (at intervals of 5\%) where raters appear to prefer specific values when estimating area, but not count. 
estimate disease severity $<10 \%$ compared to NPPs, and thus show better agreement over this range of disease severity. Why PP estimates of $\% \mathrm{CN}$ were less accurate $($ slope $=0.74)$ compared to NPPs $($ slope $=$ 0.97) was less clear. However, the number of representatives in each group was different, with only five of the 28 raters being PPs, so the range of ability for NPPs was doubtless better represented in this study and might have resulted in a more accurate NPP mean estimate. The mean estimates for all 28 raters also indicated estimation ability for symptoms types and common sources of error. Lin's concordance correlation coefficient showed the individual estimates of LN were so precise and accurate that there was little improvement in precision or accuracy when the individual data were averaged (Fig. 4). The average of all 28 rater estimates for $\% \mathrm{~N}$ and $\% \mathrm{CN}$ had improved precision (Fig. 5) compared to most individual raters, but only mean $\% \mathrm{CN}$ appeared to show better accuracy

Table 6. General linear modeling analysis ${ }^{\mathrm{a}}$ and regression of the relationship between the individual estimates (and mean estimates) and true disease by a group of plant pathologists (PP) trained in disease severity assessment compared to a group of citrus canker survey personnel (NPP) not trained in disease severity assessment procedure

\begin{tabular}{llcccc}
\hline \multirow{2}{*}{$\begin{array}{l}\text { Dependent } \\
\text { variable type }\end{array}$} & Class difference $^{\mathbf{b}}$ & Group & Intercept & Slope & $\boldsymbol{r}^{\mathbf{2}}$ \\
\hline Lesion number & $24_{1,5377} P<0.0001$ & $\mathrm{PP}$ & $-0.38^{*}$ & $0.95^{* * *}$ & 0.92 \\
& $\left(7_{1,396} P=0.0087\right)$ & $\mathrm{NPP}$ & $-0.30^{* * *}$ & $0.99^{* * *}$ & 0.94 \\
$\% \mathrm{~N}$ & $161_{1,5359} P<0.0001$ & $\mathrm{PP}$ & $0.71^{* * *}$ & $1.18^{* * *}$ & 0.61 \\
& $\left(194_{1,396} P<0.001\right)$ & $\mathrm{NPP}$ & $0.76^{* * *}$ & $2.16^{* * *}$ & 0.45 \\
$\% \mathrm{CN}$ & $71_{1,5357} P<0.0001$ & $\mathrm{PP}$ & $1.37^{* * *}$ & $0.74^{* * *}$ & 0.73 \\
& $\left(79_{1,396} P<0.0001\right)$ & $\mathrm{NPP}$ & $1.47^{* * *}$ & $0.97 * * *$ & 0.58 \\
\hline
\end{tabular}

a Analysis performed on individual estimates and mean estimates of groups. Mean data are in parentheses. Group size for plant pathologists $n=5$, and for surveyors $n=23 . P>F$. ***, $P<0.001$; **, $P$ $<0.01$; $*, P<0.05$. Regression analysis performed on all individual data for each group, $r^{2}=$ coefficient of determination.

${ }^{\mathrm{b}}$ Slope, test for interaction of class*regressor, $P>F$ (mean data in parentheses).

${ }^{\mathrm{c}}$ Regression model $y=a+b x$.

$\left(C_{b}\right)$ compared to most individual raters. Thus, precision was the most improved by averaging the 28 individual rater percent area estimates for each leaf. The observation that accuracy of percent area estimates did not improve as much as precision probably indicates a common and consistent source of error among raters - such as the tendency to overestimate at true disease severities $<10 \%(6,38)$, particularly obvious considering the scale and location shifts for $\% \mathrm{~N}$.

Individually, the 28 raters varied in agreement of the estimates to the true values as demonstrated by the correlation coefficients, coefficients of determination, slope parameters, and parameters from Lin's concordance correlation analysis. Estimates of citrus canker severity made by all raters showed that error was least when dealing with counts of lesion number, followed by estimation of \% $\%$, and least good when estimating a subcategory of symptoms-the $\% \mathrm{~N}$ alone (although values of $\% \mathrm{~N}$ were low and in the range known to result in maximum error when visually rated, 38). Counts of lesions are straightforward and had least error associated with them, but they take longer to perform, particularly when numbers are higher, compared to estimating area. As seen in a previous study (5), each rater was

A

Rater

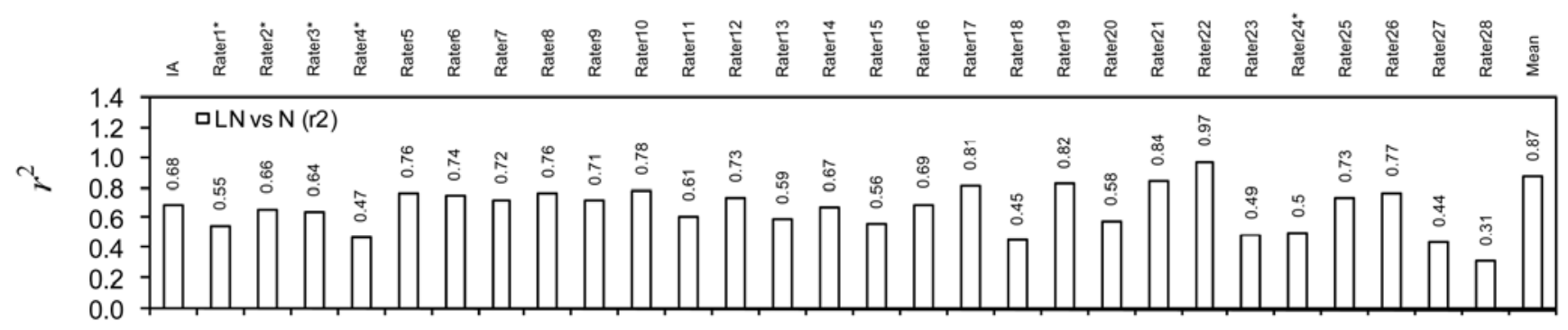

\section{B}

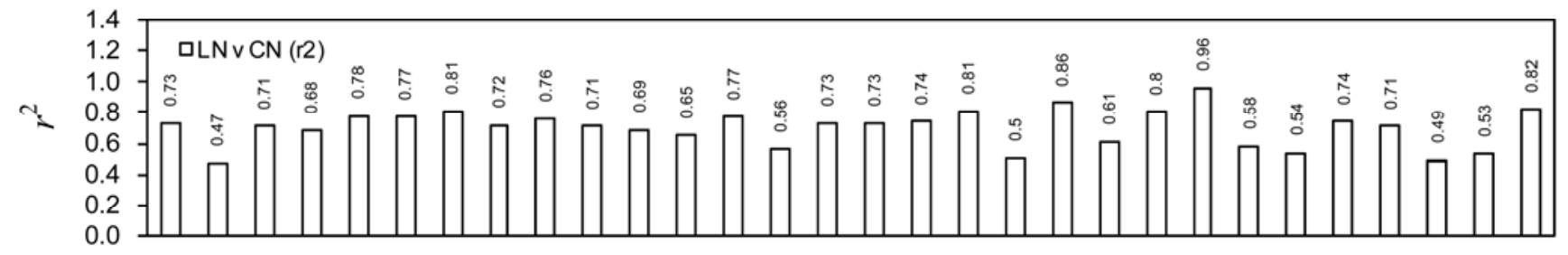

C

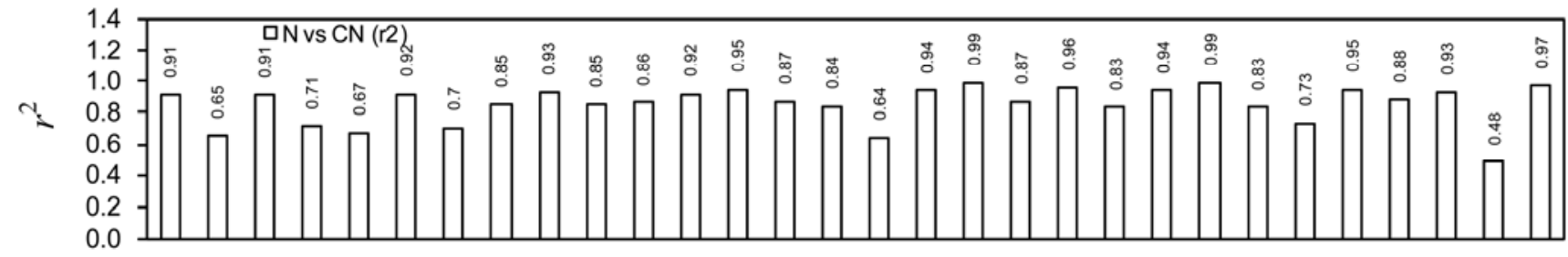

Fig. 9. Coefficients of determination $\left(r^{2}\right)$ of regression analyses of the relationship between A, lesion count vs. \% area chlorotic+necrotic (LN vs. N), B, lesion count vs. $\%$ area necrotic ( $\mathrm{LN}$ vs. $\mathrm{CN})$, and $\mathbf{C}, \%$ area chlorotic+necrotic vs. \% area necrotic $(\mathrm{N}$ vs. $\mathrm{CN})$ for severity of citrus canker symptoms on 200 grapefruit leaves assessed by image analysis and each of 28 raters. Regression model $y=a+b x$, where $x$ is the severity parameter on the $X$ axis, $a$ (intercept) and $b$ (slope) are constant parameters. * indicates trained plant pathologists. 
unique, but there were some trends and tendencies that were common among them and have been noted before $(5,6,29,31)$. Among individuals, there was a marked tendency to overestimate $\% \mathrm{~N}$ and $\% \mathrm{CN}$, particularly over the range 0 to $8 \%$. Furthermore, greater lesion number at a given true area most often resulted in overestimation of the area infected. These effects of lesion number have been commented on $(1,6,29,38)$, and considering the number of raters in this study, appear to be common traits in visual assessment of citrus canker. Individuals varied in ability and pattern for all sources of error, making it virtually impossible to effect a universal panacea for error in estimates of disease severity $(19,30)$. However, the relationship between true and estimated disease was consistently linear for all raters and measures of disease and in agreement with most other reports $(29,30)$.

There was not a particularly strong relationship between $\mathrm{LN}$ and $\% \mathrm{~N}$ or $\% \mathrm{CN}$, although the two measures of percent area infected did show a moderately good relationship. This was true for both the true data from image analysis and the data based on rater estimates. Previously observed (5) reasons might include the density of lesions which could affect actual size, age of lesions, and actual leaf area. The fact that the relationships between the true measures showed the same trends confirmed that the mediocre relationships between lesion number and area were not an artifact of the assessors, and makes the point that choice of symptoms assessed should be made relevant to the needs of the study.

Virtually all direct estimates of disease were heteroscedastic - at least over the range of true disease in this study. The residual errors of the estimates were not constant with increasing magnitude of true disease. This lends credence to some observations that variance is not constant with true disease $(6,10,15)$. Counts of greater lesion numbers might be more error prone as lesions become more crowded and coalesce, so differentiation becomes more subjective and loss of concentration more likely, resulting in greater error. Estimation of area is subject to error, and when unaided by standard area diagrams or specific training, the error is likely to be greater $(3,5,6,31,35)$. In addition, the raters appeared most willing to estimate to the nearest $1 \%$ when true disease is below $10 \%$, but at severities $>10 \%$ they tended to prefer estimates to the closest 5 or $10 \%(15,20,25,30,35 \%$, etc.). The tendency to prefer "knots" has been observed before $(5,15,22,35)$. The psychophysical factors that influence estimates of diseased area are poorly defined. Many psychophysical phenomena have been reasonably characterized using various standard methods $(2,9,16,30,39,40)$, but psychophysical tests have yet to be applied to the perception of plant disease severity across the complete range of disease ( 0 to $100 \%$ ), although a limited study has been done (30). Furthermore, several studies suggest variance of the estimate is somewhat consistent between 25 and $75 \%$ disease $(10,30)$, but variance appears to be of lesser magnitude with decreasing disease $(5,6,10,15)$, although at least one study found little effect of true disease on the error associated with the estimate (29). In the current study, variance of the disease increased with true disease in a curvilinear fashion up to $25 \%$, above which severity the data were sparse. It remains for these relationships to be fully resolved.

While area estimates of less severe disease generally had low absolute error, estimates of disease severity less than $10 \%$ area have a large relative error. Absolute error increased with true disease severity (counts of LN were least error prone), and the pronounced tendency to overestimate disease area for $\% \mathrm{~N}$ and $\% \mathrm{CN}$ at $<10 \%$ true area is likely due to illusion in area
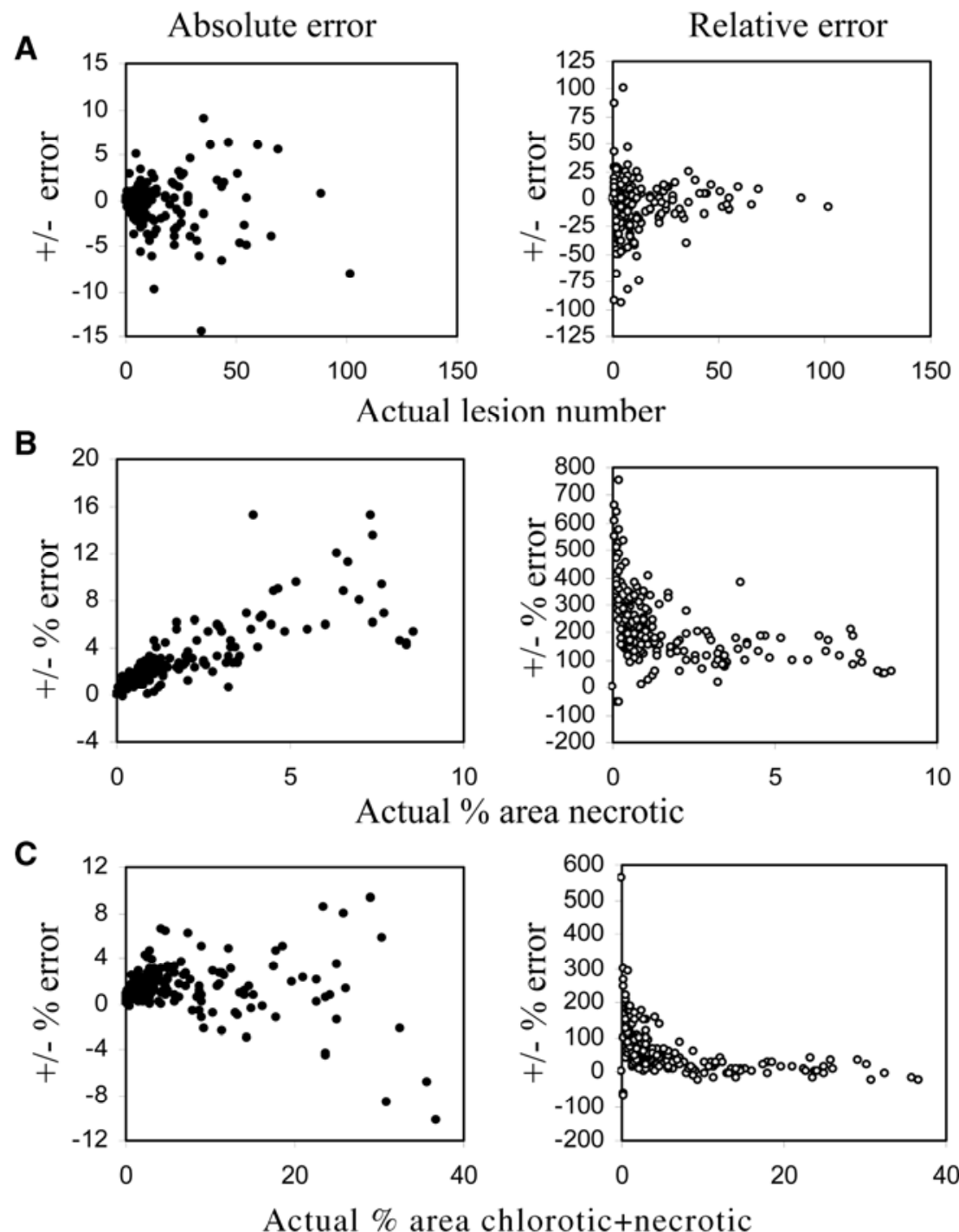

Fig. 10. Relationship between true disease and absolute and relative error for mean estimates $\mathbf{A}$, rater counts of lesions, $\mathbf{B}$, rater estimates of $\%$ area necrotic, and $\mathbf{C}$, rater estimates of $\%$ area chlorotic+necrotic on 200 leaves infected with citrus canker assessed by 28 raters.

estimation already noted in this study. At severity above $10 \%$ area, there was a small, almost equal tendency to over- or underestimate $\% \mathrm{CN}$. The high relative error associated with estimates of low disease has ramifications for the use of these data, and also the value of training or the use of standard area diagrams in disease assessment. There is an argument for improvement in ability to estimate disease at low severity, as many leaf spotting diseases occur at $<35 \%$ (24).

These data show the range of abilities at estimating parameters of citrus canker severity among individuals familiar with the disease, but with different training and experience of estimating the area infected. The true data were generated using image analysis on a leaf-by-leaf basis. Image analysis also has potential for measuring disease severity automatically (27). However, disease assessment by raters will remain a very important way of assessing most diseases, and as we fully understand the relationships and sources of error, the

\section{Actual \% area chlorotic+necrotic}


development and targeting of training will be enhanced.

\section{LITERATURE CITED}

1. Amanat, P. 1976. Stimuli effecting disease assessment. Agric. Conspectus Scientificus 39:27-31.

2. Baird, J. C., and Norma, E. 1978. Fundamentals of Scaling and Psychophysics. Wiley, New York.

3. Belasque Junior, J., Bassanezi, R. B., Spósito, M. B., Ribeiro, L. M., de Jesus Júnior, W. C., and Amorim, L. 2005. Escalas diagramáticas para avaliação da severidade do cancro cítrico. Fitopatol. Bras. 30:387-393.

4. Berger, R. D. 1980. Measuring disease intensity. Pages 28-31 in: Crop Loss Assessment. Proc. E. C. Stackman Commemorative Symposium. Misc. Publ. 7. Agric. Exp. Stn., University of Minnesota, St. Paul.

5. Bock, C. H., Parker, P. E., Cook, A. Z., and Gottwald, T. R. 2008. Visual rating and the use of image analysis for assessing different symptoms of citrus canker on grapefruit leaves. Plant Dis. 92:530-541.

6. Bock, C. H., Parker, P. E., Cook, A. Z., and Gottwald, T. R. 2008. Characteristics of the perception of different severity measures of citrus canker and the relationships between the various symptom types. Plant Dis. 92:927-939.

7. Daamen, R. A. 1986. Measures of disease intensity in powdery mildew (Erysiphe graminis) of winter wheat. 1. Errors in estimating pustule number. Neth. J. Plant Pathol. 92:197-206.

8. Deinelt, M. M., and Lawson, R. H. 1989. Histopathology of Xanthomonas campestris pv. citri from Florida and Mexico in woundinoculated detached leaves of Citrus aurantifolia: Transmission electron microscopy. Phytopathology 79:336-348.

9. Ehrenstein, W. H., and Ehrenstein, A. 1999. Psychophysical Methods. Pages 1211-1241 in: Modern Techniques in Neuroscience Research. U. Windhorst and H. Johansson, eds. SpringerVerlag, Berlin.

10. Forbes, G. A., and Jeger, M. J. 1987. Factors affecting the estimation of disease intensity in simulated plant structures. Z. Pflanzenk. Pflanzen. 94:113-120.

11. Forbes, G. A., and Korva, J. T. 1994. The effect of using a Horsfall-Barratt scale on precision and accuracy of visual estimation of potato late blight severity in the field. Plant Pathol. 43:675-682.

12. Gottwald, T. R., Graham, J. H., Civerolo, E. L., Barrett, H. C., and Hearn, C. J. 1993. Differential host range reaction of citrus and citrus relatives to citrus canker and citrus bacterial spot determined by leaf mesophyll susceptibility. Plant Dis. 77:1004-1009.

13. Gottwald, T. R., and Irey, M. 2007. Posthurricane analysis of citrus canker II: Predictive model estimation of disease spread and area potentially impacted by various eradication protocols following catastrophic weather events. Online. Plant Health Progress. http:// www.apsnet.org/online/feature/hurricane/.

14. Graham, J. H., Gottwald, T. R., and Fardelmann, D. 1990. Cultivar-specific interactions for strains of Xanthomonas campestris from Florida that cause citrus canker and citrus bacterial spot. Plant Dis. 74:753-756.

15. Hau, B., Kranz, J., and Konig, R. 1989. Fehler beim Schätzen von Befallsstärken bei Pflanzenkrankheiten. Z. Pflanzenk. Pflanzen. 96: 649-674.

16. Helson, H., and Bevan, W. 1964. An investigation of variables in judgments of relative area. J. Exp. Psychol. 67:335-341.

17. Herbert, T. T. 1982 . The rationale for the Horsfall-Barratt plant disease assessment scale. Phytopathology 72:1269.

18. Horsfall, J. G. 1945. Fungicides and their action. Annales Cryptogamica et Phytopathologici, Vol. II. Chronica Botanica, Waltham, MA.

19. Horsfall J. G., and Barrat, R. W. 1945. An improved grading system for measuring plant disease. (Abstr.) Phytopathology 35:655.

20. Horsfall, J. G., and Cowling, E. B. 1978. Pathometry: The measurement of plant disease. Pages 120-136 in: Plant Disease: An Advanced Treatise, Vol. II. J. G. Horsfall and E. B. Cowling, eds. Academic Press, New York.

21. Irey, M. S., Gottwald, T. R., Graham, J., Riley, T., and Carlton, G. 2006. Post-hurricane analysis of citrus canker spread and progress towards the development of a predictive model for future weather related spread. Plant Health Progress. doi:10.1094/PHP-2006-0822-01-RS.

22. Koch, H., and Hau, B. 1980. Ein psychologischer aspect beim schatzen von pflanzenkrankheiten. Z. Pflanzenk. Pflanzen. 87:587-593.

23. Koizumi, M. 1976. Behavior of Xanthomonas citri (Hasse) Dowson in the infection process I. Multiplication of the bacteria and histological changes following needle prick inoculation. Ann. Phytopathol. Soc. Jpn. 42:407-416.

24. Kranz, J. 1988. Measuring plant disease. Pages 35-50 in: Experimental Techniques in Plant Disease Epidemiology. J. Kranz and J. Rotem, eds. Springer-Verlag, New York.

25. Lin, L. I.-K. 1989. A concordance correlation coefficient to evaluate reproducibility. Biometrics 45:255-268.

26. Madden, L. V., Hughes, G., and van den Bosch, F. 2007. The Study of Plant Disease
Epidemics. American Phytopathological Society, St. Paul, MN.

27. Martin, D. P., and Rybicki, E. P. 1998. Microcomputer-based quantification of maize streak virus symptoms in Zea mays. Phytopathology 88:422-427.

28. Newton, A. C., and Hackett, C. A. 1994. Subjective components of mildew assessment on spring barley. Eur. J. Plant Pathol. 100:395412.

29. Nita, M., Ellis, M. A., and Madden, L. V. 2003. Reliability and accuracy of visual estimation of Phomopsis leaf blight of strawberry. Phytopathology 93:995-1005.

30. Nutter, F. W., Jr., and Esker, P. D. 2006. The role of psychophysics in phytopathology. Eur. J. Plant Pathol. 114:199-213.

31. Nutter, F. W., Jr., and Schultz, P. M. 1995 Improving the accuracy and precision of disease assessment: Selection of methods and use of computer-aided training programs. Can. J. Plant Pathol. 17:174-178.

32. Nutter, F. W., Jr., Teng, P. S., and Shokes, F. M. 1991. Disease assessment terms and concepts. Plant Dis. 75:1187-1188.

33. Nutter, F. W., Jr., Esker, P. D., and Coelho Netto, R. A. 2006. Disease assessment concepts in plant pathology and the advancements made in improving the accuracy and precision of plant disease data. Eur. J. Plant Pathol. 115:95-103.

34. Nutter, F. W., Jr., Gleason, M. L., Jenco, J. H., and Christians, N. C. 1993. Assessing the accuracy, intra-rater repeatability, and inter-rater reliability of disease assessment systems. Phytopathology 83:806-812.

35. Parker, S. R., Whelan, M. J., and Royle, D. J. 1995. Reliable measurement of disease severity. Asp. App. Biol. 43:205-214.

36. Schubert, T. S., Gottwald, T. R., Rizvi, S. A Graham, J. H., Sun, X., and Dixon, W. N. 2001. Meeting the challenge of eradicating citrus canker in Florida - again. Plant Dis. 85:340-356

37. Shaw, M. W., and Royle, D. J. 1989. Estimation and validation of a function describing the rate at which Mycosphaerella graminicola causes yield loss in winter wheat. Ann. Appl. Biol. 115:425-442.

38. Sherwood, R. T., Berg, C. C., Hoover, M. R., and Zeiders, K. E. 1983. Illusions in visual assessment of Staganospora leaf spot of orchardgrass. Phytopathology 73:173-177.

39. Stevens, S. S. 1961. To honor Fechner and repeal his law. Science 133:80-86.

40. Stevens, S. S., and Guirao, M. 1963. Subjective scaling of length and area and the matching of length to loudness and brightness. J. Exp. Psychol. 66:177-186. 